\title{
Efectos adversos provocados en la descendencia de Drosophila melanogaster Meigen inducidos por antibióticos usados en salmonicultura
}

\section{Adverse effects caused in offspring of Drosophila melanogaster Meigen induced by antibiotics used in salmon farming}

\author{
Oscar A. Benavides, Fidelina González ${ }^{1 *}$, Katia Sáez ${ }^{3}$, Ruth Chávez ${ }^{1}$ \& Magda Hernández ${ }^{2}$ \\ ${ }^{1}$ Departamento de Biología Celular, Facultad de Ciencias Biológicas, Universidad de Concepción, Casilla 160-C, Concepción, \\ Chile. \\ ${ }^{2}$ Departamento de Microbiología, Facultad de Ciencias Biológicas, Universidad de Concepción, Casilla 160-C, Concepción, \\ Chile. \\ 32Departamento de Estadística, Facultad de Ciencias Físicas y Matemáticas, Universidad de Concepción, Casilla 160-C, \\ Concepción, Chile. \\ *fgonzale@udec.cl
}

\begin{abstract}
RESUMEN
La administración de antibióticos en las salmonicultoras en Chile facilita la acumulación en el ambiente marino afectando la biota. En 2016 se utilizaron 382 toneladas de antibióticos (oxitetraciclina y florfenicol). Se evaluó la actividad biológica de florfenicol y oxitetraciclina en larvas de Drosophila melanogaster Meigen en condiciones de laboratorio. Se aplicó un diseño experimental completamente aleatorio en los bioensayos con 10 tratamientos $(0,3 ; 0,6$ y 1,2 mg/mL de florfenicol y 0,$3 ; 0,6 ; 0,8 ; 1,2 ; 1,6$ y $3,2 \mathrm{mg} / \mathrm{mL}$ de oxitetraciclina) aplicados a la generación parental, con dos repeticiones. Se evaluó la mortalidad, efectos sobre el ciclo de vida, análisis de sustrato y observación de organismos en la generación parental y en dos generaciones sucesivas. Los resultados indican que a mayor concentración de antibiótico aplicado a la generación parental, la mortalidad aumenta en la primera generación y los ciclos de vida se retrasan en las siguientes generaciones; además, aumenta la frecuencia de aparición de adultos con alteraciones morfológicas del ala; en el sustrato alimenticio cambia el color y el $\mathrm{pH}$ en todos los tratamientos. Ambos antimicrobianos tienen efectos adversos sobre el desarrollo de Drosophila melanogaster y sobre el medio de cultivo. El efecto de los antibióticos en la generación parental es heredable, en dos generaciones sucesivas, que tuvieron disminución en el número de crías e individuos con alas deformadas o ausentes. Los antibióticos afectarían directamente a la vida silvestre que rodea los centros de cultivo del salmón, lo que debería controlarse para evitar un daño ambiental importante.
\end{abstract}

Palabras claves: Antibióticos, salmonicultura, bioensayos, Drosophila melanogaster.

\begin{abstract}
The administration of antibiotics by salmon farms in Chile, facilitates the accumulation in the marine environment, affecting the biota. In 2016, 382 tons of antibiotics (oxytetracycline and florfenicol) were used. In this atudy, the biological activity of florfenicol and oxytetracycline in larvae of Drosophila melanogaster Meigen, was evaluated under laboratory conditions. A completely randomized experimental design was applied in the bioassays with 10 treatments $(0.3,0.6 \mathrm{and} 1.2 \mathrm{mg} / \mathrm{mL}$ of florfenicol and $0.3,0.6,0.8,1.2,1.6$ and $3.2 \mathrm{mg} / \mathrm{mL}$ of oxytetracycline) applied to the parental generation, with two repetitions. Mortality, effects on the life cycle, substrate analysis and observation of organisms in the parental generation, and in two successive generations were evaluated. The results indicate that the higher the concentration of antibiotic applied to the parental generation, the mortality increases in the first generation and the life cycles are delayed in the following generations; in addition, it increases the frequency of appearance of adults with morphological alterations of the wing; the food substrate changes the color and $\mathrm{pH}$ in all treatments. Both antimicrobials have adverse effects on the development of Drosophila melanogaster and on the culture medium. The effect of antibiotics on the parental generation is inheritable, in two successive generations, that had decrease in the number of offspring and individuals with deformed or absent wings. Antibiotics would directly affect the wildlife surrounding the salmon farming centers, which should be controlled to avoid significant environmental damage.
\end{abstract}

KEYworD: Antibiotics, salmon farming, bioassay, Drosophila melanogaster. 


\section{INTRODUCCIÓN}

En Chile, la salmonicultura se introdujo a principios del siglo XX. Los cultivos de salmón se intensificaron a gran escala, en los años 80 cuando el país se posicionó como el segundo productor mundial, después de Noruega (Barton \& Floysand 2010; Muñoz 2009; Fortt et al. 2007; Soto \& Norambuena 2004).

En el proceso productivo, los salmones crecen en agua salada y se reproducen en agua dulce (Salgado 2005). El transporte de salmones de un ambiente a otro, favorece el contacto entre diferentes poblaciones, facilitando la infección cruzada y contagio de enfermedades, provocando pérdidas económicas para la industria (Ibieta et al. 2011; Bravo et al. 2005). En el control de patógenos de cultivos intensivos, se mezcla antibióticos con el alimento ingerido por los peces (Sørum 2006; Bravo et al. 2005), sin embargo se recomiendan ajustes al protocolo para ser compatible con el entorno ambiental (Cabello 2003).

Los antibióticos inhiben el crecimiento (actividad bacteriostática) y/o matan bacterias (actividad bactericida), se emplean en el tratamiento de enfermedades en seres humanos y animales en cautiverio. Su uso ha ido en aumento en muchos países (Cabello 2006; Sarmah et al. 2006; Boxall et al. 2004). Se aplican directamente en el agua o en el alimento de los peces (Shao 2001; Hirsch et al. 1999). Los antibióticos o sus metabolitos y/o productos de degradación llegan al ambiente circundante causando efectos ecológicos adversos como selección de bacterias resistentes, toxicidad para la microflora (afectando la diversidad biológica del fitoplancton) y/o microfauna (afectando las comunidades de zooplancton) (Ferreira 2007; Christensen et al. 2006; Cabello 2006; Rigos et al. 2004; Wollenberger et al. 2000; Lützhøft et al. 1999). Estos cambios en la diversidad pueden afectar potencialmente la salud de los animales al causar inmunodepresión (Cabello 2003; Morris 1999).

La selección de bacterias resistentes provocada por el uso continuo de antimicrobianos ocasiona un problema sanitario que afecta a peces y seres humanos que los consumen (González et al. 2013, Miranda 2012; Millanao et al. 2011; Burridge et al. 2010). Las relaciones ecológicas se modifican, debido a la toxicidad para la vida silvestre (organismos invertebrados) planteando serias interrogantes sobre las especies que circundan los alrededores de las jaulas salmoneras (Salgado et al. 2015; Fortt et al. 2007; Halling-Sørensen et al. 2000; Dölz 2001; Baguer et al. 2000; Migliore et al. 1997; Coyne et al. 1997). Definidos como microcontaminantes ambientales (Le Bris \& Pouliquen 2004), presentes en bajas concentraciones en el medio ambiente, tienen efectos probables a largo plazo por exposición de las sucesivas generaciones de poblaciones de especies en el ecosistema (Kümmerer 2009; HallingSørensen et al. 1998). El 80\% de los antimicrobianos llegan al ambiente marino en forma no absorbida (Buschmann et al.
2012) a través de las excreciones de peces (Le \& Munekage 2004; Burka et al. 1997; Capone et al. 1996), se acumulan depositándose por gravedad en los sedimentos circundantes a los cultivos (Buschmann et al. 2009; Pelletier et al. 2009; Sapkota et al. 2008; Sarmah et al. 2006). La circulación hídrica los distribuye a lugares alejados de los sistemas de cultivo, afectando a detritívoros y peces silvestres (robalos, cabrillas), que consumen los antibióticos a través de la ingesta alimentaria (Buschmann et al. 2009, 2006; Sørum 2006; Coyne et al. 1997; Kerry et al. 1996).

A nivel mundial existen 24 países productores, siendo los principales Noruega, Chile, Escocia y Canadá (FAO 2010). En los últimos 20 años han mejorado las prácticas de gestión y crianza de peces, para reducir el uso de antibióticos y modificar la forma de administración, por el riesgo para la salud humana y la biota marina. Las empresas salmoniculturas noruegas en 2007 utilizaron aproximadamente $0,0008 \mathrm{~kg}$ de antimicrobianos por cada tonelada de salmón producido. El mismo año en Chile se utilizó 1,4 kg por tonelada (Millanao et al. 2011; Burridge et al. 2010; Gómez 2009; SalmonChile 2008), 170 veces más que Noruega (Millanao et al. 2011; Burridge et al. 2010; Gómez 2009; Barrientos 2006; Millanao 2002). En el periodo 2011-2013 se utilizaron aproximadamente 995,49 toneladas de diversos agentes antibacterianos en Chile, de los cuales 450,7 toneladas corresponden sólo al año 2013. En 2014 aumentó un 25\% llegando a 563,2 toneladas. En 2016, disminuyó a 382 ton, (31\% menos que en 2015), en tanto en Noruega usaron $523 \mathrm{~kg}$, produciendo el doble de salmones que en Chile. En Chile, un 96\% se administró en centros marinos y un $4 \%$ en centros de agua dulce (SERNAPESCA 2017).

En la salmonicultura Chilena hay un uso generalizado de dos antibióticos que comprende el 98\% del volumen total de antibióticos, florfenicol (63\%) y oxitetraciclina (35\%), ambos de amplio uso veterinario (Millanao et al. 2011). Florfenicol es un antibacteriano bacteriostático sintético, de acción sistémica y amplio espectro de acción (Bravo et al. 2005). Oxitetraciclina pertenece al grupo de las tetracicilinas, es un bacteriostático que tiene actividad contra bacterias, incluyendo micoplasmas y rickettsias (Coyne et al. 1997; Capone et al. 1996). Drosophila melanogaster Meigen, es un insecto cosmopolita de casi $2 \mathrm{~mm}$ de largo, y por su alto índice de prolificidad y fácil manejo en el laboratorio presenta ventajas para la aplicación de un alto nivel de rigor estadístico en el análisis de los experimentos (Artigas 1998). Presenta diferentes etapas de desarrollo (huevo, tres estadios larvales, pupa e imago) (Demerec \& Kaufmann 1969). La fase larvaria en medios de cultivo tiene la potencialidad de ser sometida a bioensayos con diferentes condiciones experimentales, que pueden ser evaluadas en la fase adulta y en generaciones sucesivas. Los impactos ambientales de la salmonicultura en el país, en relación con su nivel de producción han sido analizados desde una mirada objetiva 
por varios autores (Guillén et al. 2012; Buschmann et al. 2009; Kim et al. 2008). Investigar, regular y educar a quienes son responsables en esta materia, son los desafíos a mediano y a corto plazo, de lo contrario nuestra biota marina que sustenta cadenas tróficas y nuestros recursos naturales, se verán cada vez más expuestas a estos agentes que alteran sus ciclos normales de desarrollo. El objetivo de esta investigación es evaluar la actividad biológica del florfenicol y la oxitetraciclina, dos de los antibióticos más usados en Salmonicultura en Chile, sobre una generación parental de insectos (larvas de Drosophila melanogaster) y su descendencia bajo condiciones de laboratorio y evaluar el efecto en parentales y dos generaciones sucesivas. Usando este modelo se puede establecer el efecto potencial de los antibióticos sobre la vida en el entorno próximo o alejado de las jaulas salmoneras.

\section{MATERIALES Y MÉTODOS}

\section{ANTIBIÓTICOS}

Florfenicol es un antibiótico de amplio espectro (Samuelsen \& Bergh 2004; Nordmo et al. 1994). A pH 7, la solubilidad (en agua) de este compuesto es de 1,32 mg/mL. En peces, el régimen de tratamiento recomendado es de $10 \mathrm{mg} / \mathrm{kg}$ de florfenicol durante 10 días administrado en el alimento (San Martin et al. 2015). El florfenicol se mantuvo a temperatura ambiente, entre 15 y $30^{\circ} \mathrm{C}$, en lugar seco y protegido de la luz solar.

La oxitetraciclina es un antibiótico de amplio espectro, utilizado para el tratamiento de enfermedades bacterianas en acuicultura, por su eficacia, bajo costo y amplio espectro de acción (Reed et al. 2004; Ueno et al. 2004; Miranda \& Zemelman 2002; Rigos et al. 2002). En peces, el régimen de tratamiento recomendado es de $94 \mathrm{mg} / \mathrm{kg}$ de oxitetraciclina por un período de 10 días administrado en el alimento (San Martin et al. 2015). Esta substancia (Veterquimica SA) se mantuvo a temperatura ambiente, entre 15 y $30^{\circ} \mathrm{C}$, en lugar seco y protegido de la luz solar previo a su uso en este estudio.

DETERMINACIÓN DE LAS CONCENTRACIONES DE ANTIBIÓTICOS USADAS EN BIOENSAYOS

Cien larvas en estadío II de Drosophila melanogaster, se pesaron en balanza analítica (marca RevelElectronicBalance, modelo XY2000C). La concentración de florfenicol usada para los ensayos se determinó estableciendo una relación entre la dosis por kg de pez (San Martín et al. 2015) y el peso promedio de 100 larvas. La concentración equivalente calculada para larvas de Drosophila melanogaster es de 0,3 $\mathrm{mg} / \mathrm{mL}$. En los bioensayos se usó el doble $(0,6 \mathrm{mg} / \mathrm{mL})$ y el cuádruple $(1,2 \mathrm{mg} / \mathrm{mL})$ de la concentración calculada sobre la base de la dosificación recomendada (San Martin et al.
2015). La concentración de oxitetraciclina usada en peces y calculada sobre la base del peso de las larvas de Drosophila melanogaster equivale a $0,8 \mathrm{mg} / \mathrm{mL}, 1,6 \mathrm{mg} / \mathrm{mL}$ y $3,2 \mathrm{mg}$ / $\mathrm{mL}$. El control se hizo con agar-agar, usado como matriz sin antibiótico, sobre la mezcla del alimento.

CONCENTRACIÓN DE AGAR-AGAR EN MATRIZ QUE CONTIENE EL ANTIBIÓTICO EN EL MEDIO DE CULTIVO DE LARVAS DE DROSOPHILA MELANOGASTER

Para asegurar que hay una distribución homogénea de la concentración del antibiótico sobre el medio gelatinoso que contiene el alimento de la larva, es necesario incluirlo en una matriz de agar. Con el fin que la larva pueda a la vez entrar en contacto y alimentarse incorporando el antibiótico e introducirse con facilidad en este medio, para asegurar reproducibilidad del experimento, la incorporación del antibiótico en la ingesta de la larva y su alimentación, necesaria para su crecimiento y metamorfosis. La concentración del agar-agar a usar, va a determinar la fuerza del coloide y con esto las restricciones potenciales a la capacidad de excavación de larvas (Godoy-Herrera 2001) en el gel y probablemente la absorción a nivel del digestivo. Se ensayaron las concentraciones de 0,10, 0,20 y 0,40 g de agar-agar en $100 \mathrm{~mL}$ de agua destilada. Se vertieron alícuotas de $5 \mathrm{~mL}$ en placas de Petri y luego de formado el gel, y se depositaron 5 larvas estadío II en cada una, para observar y contar, después de una hora, cuantas habían atravesado el sustrato.

EVALUACiÓn DE LA Distribución Homogénea de Antibióticos EN LA MATRIZ DE AGAR-AGAR

Alícuotas de $5 \mathrm{~mL}$ del gel fueron vertidas en tubos de centrifuga (Falcón) y mezcladas con el antibiótico para cada concentración, en triplicado, con agitación en Vórtex, durante dos minutos para asegurar distribución homogénea del antibiótico en el gel. Se vertió en placas Petri y se dejó reposar. Este preparado fue utilizado para la elaboración de pruebas de susceptibilidad por difusión en agar, utilizando discos de agar que contiene el antibiótico vertido sobre la superficie del medio de cultivo de larvas de Drosophila melanogaster, con el fin de verificar la distribución homogénea del antibiótico en el medio de cultivo de larvas de Drosophila melanogaster.

PRUEBAS DE SUSCEPTIBILIDAD POR DIFUSIÓN EN AGAR, UTILIZANDO DISCOS DE AGAR DEL MEDIO DE CULTIVO DE LARVAS DE DROSOPHILA MELANOGASTER

La distribución homogénea del antibiótico, en la matriz de agar-agar utilizada que contiene el antibiótico, se comprobó con pruebas de susceptibilidad por difusión en agar del antibiótico, en discos de agar-agar tomados con sacabocados, desde distintos puntos del gel contenido en la placa Petri, para cada antibiótico por separado y en triplicado, en las tres concentraciones ensayadas y en el 
control, utilizando 3 cepas bacterianas mantenidas en el Cepario del Departamento de Microbiología de la Facultad de Ciencias Biológicas de la Universidad de Concepción $(E$. coli $\mathrm{K}-12$, E. coli $\mathrm{SI}$ y $S$. aureus $6538 \mathrm{P})$, a $37{ }^{\circ} \mathrm{C}$ por $18 \mathrm{~h}$ de incubación en estufa, al cabo del cual se midió el diámetro de los halos de inhibición. Estos ensayos se realizaron de acuerdo a recomendaciones sugeridas por el Instituto de Salud Pública (Araya et al. 2002).

\section{Grupo PARENTAL De DROSOPHILA MELANOGASTER}

Se utilizó como modelo biológico la cepa silvestre Drosophila melanogaster (cepa "santiago") disponible en el Cepario de Drosophila melanogaster, del Laboratorio de Genética del Departamento de Biología Celular, Facultad de Ciencias Biológicas, Universidad de Concepción, Chile. Esta cepa se cultiva fácilmente en botellas estériles con medio de cultivo gelatinoso para alimentación, crecimiento y desarrollo de las larvas. Una pareja puede tener 200 ó más descendientes, y puede obtenerse una generación cada 10 ó 14 días. La temperatura óptima de cultivo es a $25^{\circ} \mathrm{C}$ (Storer et al. 2001). La fase larvaria Drosophila melanogaster consiste de tres estadios. Entre 24 y $96 \mathrm{~h}$ de desarrollo a partir de huevo, se obtienen las larvas en estadío II, usadas para iniciar los bioensayos. La larva de Drosophila se alimenta ingiriendo el alimento con una gran voracidad (Sewell et al. 1975), hasta alcanzar un peso mínimo para pupar y dar origen al adulto (Powell 1997).

\section{Sustrato}

El medio de cultivo utilizado para el mantenimiento de Drosophila melanogaster se elaboró con agua destilada, agar-agar, sémola, levadura seca, ácido salicílico, azúcar y mezcla ácida $\left(\mathrm{NaNO}_{3}, \mathrm{~K}_{2} \mathrm{HPO}_{4}, \mathrm{KCl}, \mathrm{MgSO}_{4}\right.$ y $\left.\mathrm{FeSO}_{4}\right)$. $\mathrm{La}$ mezcla se introdujo en frascos de cultivo (30 $\mathrm{mL}$ aprox.) esterilizados en autoclave (Demerec \& Kaufmann 1969; DeBach 1968).

Bioensayos de los antibióticos en larvas de Drosophila MELANOGASTER

Para evaluar el efecto de los antibióticos se realizaron bioensayos de toxicidad, en larvas estadío II de la cepa silvestre (denominada cepa "santiago") de Drosophila melanogaster, siguiendo el protocolo desarrollado anteriormente (Suazo et al. 2012). La reproducción de los insectos se llevó a cabo en frascos de vidrio de $250 \mathrm{~mL}$ de capacidad, tapados con un algodón hidrófobo, envuelto en una gasa con el fin de permitir el intercambio gaseoso. Estos frascos se mantuvieron en una cámara con las condiciones óptimas de desarrollo de los individuos, a una temperatura aproximada de $25^{\circ} \mathrm{C}$ y con iluminación normal. Se controló la hidratación y la aparición de hongos en el medio de cultivo. De esta forma se pudo asegurar que la mortalidad obtenida es únicamente producto de la toxicidad del tratamiento evaluado.
Homogeneización GenÉticA DE LA CEPA

Se realizó la homogeneización genética de la cepa para disponer de una población de individuos estandarizados desde el punto de vista genético y fenotípico. En un frasco con medio de cultivo se depositaron los parentales $(P)$ cinco hembras vírgenes y cinco machos, de la cepa silvestre "santiago". Tras emerger las larvas de tercer estado o pupa se eliminaron los parentales, dejando en el frasco sólo la progenie obtenida. De esta progenie $\left(F_{l}\right)$ se tomaron 10 hembras y 10 machos y se depositaron en un nuevo frasco de cultivo. Siguiendo la metodología anterior se obtuvo la segunda generación filial $\left(F_{2}\right)$. De esta nueva progenie, se recolectaron 10 parejas y realizando los mismos procedimientos se obtuvo al final de este nuevo proceso una tercera generación $\left(F_{3}\right)$, con cuyos individuos se experimentó.

\section{TRATAmientos}

Se evaluó la actividad biológica de florfenicol y oxitetraciclina en bioensayos en triplicado. En los ensayos usando florfenicol, las concentraciones fueron de $0,3 \mathrm{mg} /$ $\mathrm{mL}, 0,6 \mathrm{mg} / \mathrm{mL}$ y $1,2 \mathrm{mg} / \mathrm{mL}$. Las concentraciones de oxitetraciclina ensayadas fueron de $0,3 \mathrm{mg} / \mathrm{mL}, 0,6 \mathrm{mg} / \mathrm{mL}$, $0,8 \mathrm{mg} / \mathrm{mL}, 1,2 \mathrm{mg} / \mathrm{mL}, 1,6 \mathrm{mg} / \mathrm{mL}$ y $3,2 \mathrm{mg} / \mathrm{mL}$.

El grupo control contenía en el frasco de cultivo la mezcla alimenticia y sobre el alimento la matriz de agar-agar, sin antibiótico.

En cada frasco de vidrio $(250 \mathrm{~mL})$ se introdujeron 50 larvas de Drosophila melanogaster en estado II de la cepa silvestre homogeneizada genéticamente y se mantuvieron alrededor de 16 días en una cámara con las condiciones óptimas para el desarrollo de los individuos. Los tratamientos contemplaron dos repeticiones en el tiempo con el fin de disminuir los errores experimentales (Park et al. 2004).

\section{TASA DE MORTALIDAD DE LA GENERACIÓN PARENTAL}

La cuantificación de los adultos vivos se inició al noveno día, hasta cumplirse el día 16 en el tratamiento y el control. Una diferencia de 50 larvas por tratamiento menos los adultos vivos se asumieron como la mortalidad.

\section{Dosis Equitóxicas}

Una vez obtenida la mortalidad, se estimó la concentración letal $50 \%\left(\mathrm{CL}_{50}\right)$ con el procedimiento Probit y se transformaron las dosis a logaritmos y los porcentajes de mortalidad a valores Probit, según tablas de transformación (Finney 1952). Para la interpretación de estos resultados, se calculó la regresión lineal $(\mathrm{Y}=\mathrm{a}+\mathrm{bx})$ entre el logaritmo de la dosis (x) y los valores Probit (y). Una vez obtenida la regresión, se estimó con el modelo el valor para un $50 \%$ de mortalidad, los que en unidades probit correspondió a 5 (Finney 1952; Finney \& Stevens 1948). 
Efectos adversos de antibióticos en Drosophila melanogaster: BeNAVIDES, O. ET AL.

TABLa 1. Pruebas de susceptibilidad por difusión en agar de la matriz de agar que contiene el antibiótico en el medio de cultivo de larvas de Drosophila melanogaster (antibiótico: florfenicol) para tres cepas bacterianas: S. aureus, E. coli K-12 y E. coli SI. / Susceptibility tests by agar diffusion of the agar matrix containing the antibiotic in the culture medium of Drosophila melanogaster larvae (antibiotic: florfenicol) for three bacterial strains: $S$. aureus, E. coli K-12 and E. coli SI.

\begin{tabular}{ccccc}
\hline Cepa bacteriana & Concentración (MG/ML) & $\begin{array}{c}\text { Halo de inhibición } \\
\text { (CM) }\end{array}$ & $\begin{array}{c}\text { Desviación estándar } \\
\text { Control }\end{array}$ Susceptible (S) O $_{\text {Resistente (R) }}$ \\
\hline S. aureus & 0,240 & 0 & 0 & $\mathrm{R}$ \\
& 0,480 & 1,2 & 0,1 & $\mathrm{~S}$ \\
& 0,960 & 1,8 & 0,1 & $\mathrm{~S}$ \\
E. coli K-12 & 0,240 & 1,9 & 0,1 & $\mathrm{~S}$ \\
& 0,480 & 1,2 & 0,1 & $\mathrm{~S}$ \\
& 0,960 & 1,9 & 0,7 & $\mathrm{~S}$ \\
E. coli SI & 0,240 & 1,7 & 0,1 & $\mathrm{~S}$ \\
& 0,480 & 1,8 & 0,1 & $\mathrm{~S}$ \\
& 0,960 & 1,8 & 0,2 & $\mathrm{~S}$ \\
\hline
\end{tabular}

Tasa de nacimientos de la Primera Y Segunda Generación FILIAL

De los parentales sobrevivientes en cada uno de los tratamientos se recolectaron 5 parejas, las que fueron depositadas en un nuevo frasco de cultivo sin antibiótico y otras 5 parejas fueron reintroducidas en el frasco de cultivo con antibiótico. Los individuos restantes fueron eliminados. El registro de datos de la primera generación filial se inició 10 días después de la siembra de los individuos y se extendió hasta 16 días después. Los recuentos de adultos por sexo se llevaron a cabo cada tres días. Para la segunda generación filial, se siguieron los mismos pasos antes descritos.

Diseño Experimental Y ANÁlisis Estadístico

El diseño experimental fue completamente aleatorio. Los datos porcentuales alcanzados fueron normalizados usando la función arcoseno. Posteriormente se realizó un análisis de varianza (ANDEVA) y una prueba de comparación de medias de los tratamientos con un nivel de confianza del 95 $\%(\mathrm{P}<0,05)$ mediante la prueba de Tukey con el programa estadístico Infosat (Di Rienzo et al. 2015).

\section{ANÁLISIS DE SUSTRATO}

Transcurridos 30 días de iniciado el tratamiento, se evaluó el sustrato midiendo el $\mathrm{pH}$ y realizando una prueba de susceptibilidad por difusión en agar, usando discos del sustrato. Para medir el pH de cada sustrato, se utiliza cintas de $\mathrm{pH}$ (Merck). Para las pruebas de susceptibilidad por difusión en agar, de cada frasco, se utilizaron las cepas bacterianas Escherichia coli K-12 y Escherichia coli SI.

\section{Morfología y Estructura}

Mediante el uso de una lupa estereoscópica se observaron los insectos sometidos a ensayo, tratamiento y control para registrar la morfología y la estructura con imágenes capturadas que se obtuvieron adosando una cámara fotográfica al instrumento.

\section{RESULTADOS}

DETERMINACIÓN DE LA CONCENTRACIÓN DE AGAR-AGAR A USAR EN LA MATRIZ DE AGAR QUE CONTIENE EL ANTIBIÓTICO EN EL MEDIO DE CULTIVO DE LARVAS DE DROSOPHILA MELANOGASTER

Con el fin de asegurar que la larva depositada sobre la superficie de agar ubicada sobre el alimento, pudiera llegar a alimentarse, luego de atravesar una película de agar-agar de 1 a $2 \mathrm{~mm}$ de espesor, que funciona como matriz para contener el antibiótico, se ensayaron diferentes concentraciones de agar-agar, antes de depositarla sobre el alimento. De acuerdo a la capacidad de las larvas de Drosophila melanogaster para excavar en las diferentes concentraciones ensayadas, el 100\% de los individuos logró atravesar por completo el medio llegando a la base de la placa Petri después de una hora de ensayo (Fig. 1). La capacidad de excavación de larvas de estado II de Drosophila melanogaster fue comprobada cuando las larvas atravesaron por completo el medio hasta llegar al fondo de la placa Petri. En la preparación $\mathrm{N}^{\circ} 1(0,10$ $\mathrm{g}$ en $100 \mathrm{~mL}$ de agua destilada), la ligera consistencia del gel (estado sol) permitía que la larva llegara con facilidad al fondo de la placa (Fig. 1a). Esta opción fue descartada porque la larva podría no tener suficiente contacto con el antibiótico. En la preparación $\mathrm{N}^{\circ} 2(0,40 \mathrm{~g}$ en $100 \mathrm{~mL}$ de agua destilada), la alta consistencia del medio semisólido impedía el desplazamiento necesario de la larva para llegar al fondo de la placa Petri, demoraba demasiado tiempo en 
alcanzar el fondo (Fig. 1b). Se descartó esta alternativa, la larva podría morir de inanición antes de llegar al alimento. La preparación $\mathrm{N}^{\circ} 3(0,20 \mathrm{~g}$ en $100 \mathrm{~mL}$ de agua destilada) tenía consistencia suficiente para que la larva consumiera el agar (matriz) horadando el medio en el tiempo adecuado (Fig. 1c) asegurando el consumo del antibiótico y del alimento.

Pruebas de Susceptibilidad POR Difusión en agar de LA MATRIZ DE AGAR QUE CONTIENE EL ANTIBIÓTICO

Los resultados de las pruebas de susceptibilidad por difusión en agar del antibiótico contenido en la matriz de agar sobre tres cepas bacterianas; E. coli K-12, E. coli SI y $S$. aureus $6538 \mathrm{P}$, usando los discos de agar-agar con diferentes concentraciones de florfenicol, se muestran en la Tabla 1 donde se tabula el promedio del diámetro de los halos de inhibición de los discos de agar-agar/ florfenicol (triplicado), para cada una de las cepas ensayadas y se grafican los resultados como se puede observar en la Fig. 2, por lo tanto se comprueba reproducibilidad, el porcentaje del coeficiente de variación es menor al 10\%, exceptuando dos mediciones. De las tres cepas analizadas, S. aureus 6538P es sensible a las concentraciones ensayadas (Fig. 2a) a diferencia de E. coli K-12 y E. coli SI (Fig. 2b-2c) donde no se observa proporcionalidad entre la concentración del antibiótico y los diámetros de los halos de inhibición en distintas concentraciones ensayadas. De esta forma se asegura que la concentración del antibiótico en el agar-agar sobre superficie de la mezcla del alimento en el frasco de cultivo esté disponible para ser ingerido por las larvas junto con el alimento.
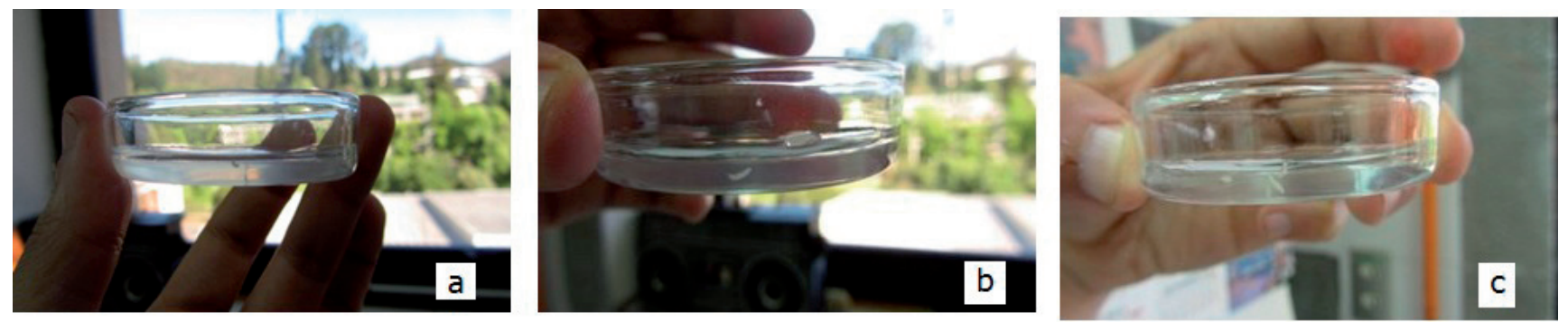

FiguRA 1. Representación gráfica de las pruebas de susceptibilidad por difusión en agar (florfenicol) en tres cepas bacterianas. a) S. aureus 6538P. b) E. coli K-12. c) E. coli SI. / Graphical representation of test of susceptibility through agar diffusion (florfenicol) in three bacterial strains. a) S. aureus 6538P. b) E. coli K-12. c) E. coli SI.
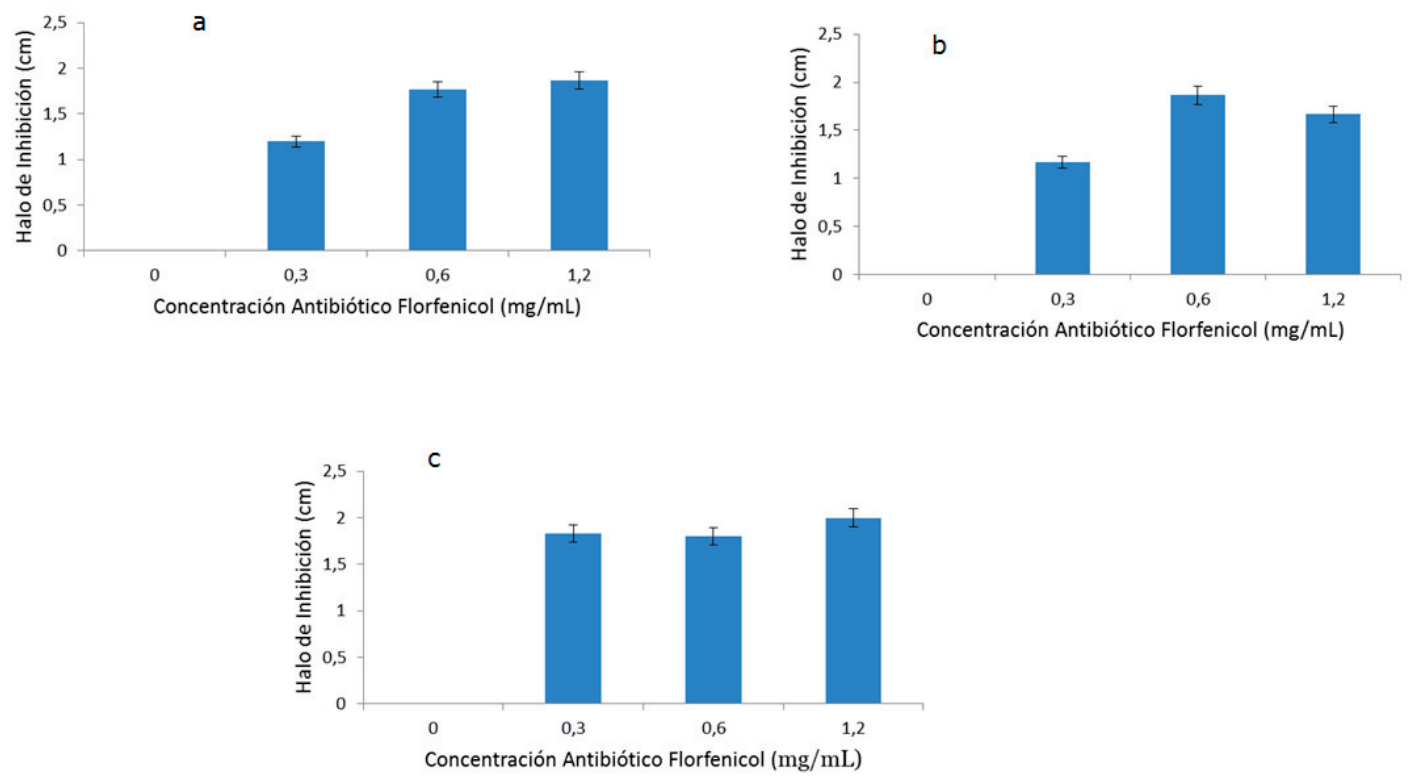

Figura 2. Capacidad de excavar de larvas de Drosophila melanogaster estadio II a distintas concentraciones de agar-agar. a) 0,10g/100mL. b) $0,40 \mathrm{~g} / 100 \mathrm{~mL}$. c) $0,20 \mathrm{~g} / 100 \mathrm{~mL}$. / Larval digging capacity of Drosophila melanogaster stage II at different concentrations of agar-agar. a) $0.10 \mathrm{~g} / 100 \mathrm{~mL}$. b) $0.40 \mathrm{~g} / 100 \mathrm{~mL}$. c) $0.20 \mathrm{~g} / 100 \mathrm{~mL}$. 
Las concentraciones de oxitetraciclina ensayadas no dieron halos de inhibición medibles, no obstante, se verificó que el antibiótico estaba presente. Las concentraciones ensayadas son demasiado altas para ser evaluadas mediante estas pruebas. No hubo crecimiento bacteriano alrededor de los discos depositados sobre las placas de ensayo de actividad bacteriana.

TOXICIDAD DE LOS ANTIBIÓTICOS EN LA GENERACIÓN PARENTAL A igual concentración de antibiótico $(0,3,0,6$ y $1,2 \mathrm{mg} / \mathrm{mL})$, el florfenicol es más letal que oxitetracilina en el grupo parental de Drosophila melanogaster. En la concentración de $1,2 \mathrm{mg} / \mathrm{mL}$ de florfenicol, el porcentaje de mortalidad en los individuos adultos es de un $28 \%$ y a la misma concentración de oxitetraciclina es de un $17 \%$, y a $0,3 \mathrm{mg} /$ $\mathrm{mL}$ de florfenicol es de $14 \%$ y para la misma concentración de oxitetraciclina es de 6\%. En el grupo control, el valor promedio es de 5\% (Fig. 3).

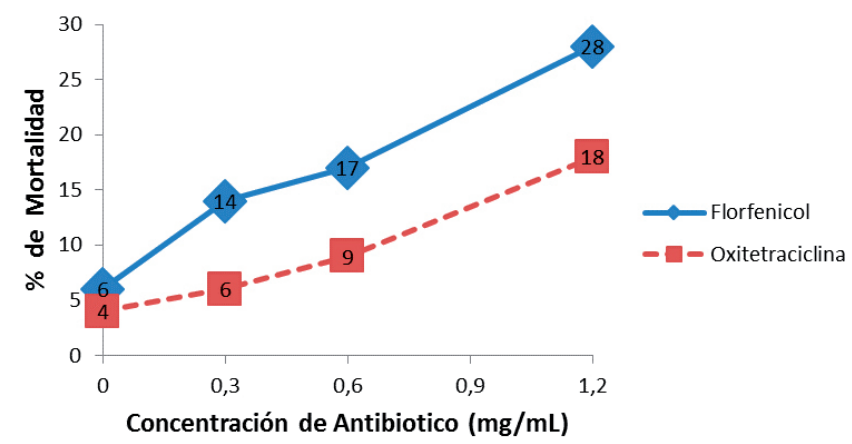

Figura 3. Porcentaje de mortalidad de individuos adultos en el grupo parental de $D$. melanogaster en concentraciones equivalentes de florfenicol y oxitetraciclina. / Percentage of mortality of adult individuals in the parental group of $D$. melanogaster in equivalent concentrations of florfenicol and oxytetracycline.

Se ensayaron 3 concentraciones diferentes en oxitetraciclina $(0,8,1,6$ y $3,2 \mathrm{mg} / \mathrm{mL})$ y los resultados se resumen en la Fig. 4. El porcentaje de mortalidad en los parentales adultos aumentó significativamente al aumentar las concentraciones del antibiótico, alcanzando un máximo de $68 \%$. El grupo control, al igual que en los tratamientos previos, no sobrepasó el 6\% de mortalidad.

\section{Dosis EQUitoxicas}

Los resultados obtenidos del análisis Probit para oxitetraciclina muestran una concentración letal $50 \%\left(\mathrm{CL}_{50}\right)$ de $2,6 \mathrm{mg} / \mathrm{mL}$. (Fig. 5).

Ciclos De VIDA EN LA GeNeración PARENTAL

En la mayoría de los tratamientos antibióticos el ciclo de vida de Drosophila melanogaster fue modificado, y los insectos demoraron más tiempo en alcanzar el estado adulto. Al comparar con el grupo control, al décimo día de tratamiento con una concentración de $1,2 \mathrm{mg} / \mathrm{mL}$ de florfenicol no se observó ningún adulto vivo. El día 13, un promedio de 17 individuos fueron contados en la concentración más alta, en tanto que en el grupo control en la misma fecha había 44 adultos. Este retraso en el desarrollo del ciclo vital del insecto se observa a concentraciones $0,3 \mathrm{mg} / \mathrm{mL}$ y $0,6 \mathrm{mg} / \mathrm{mL}$. El número de mutantes en cada concentración de florfenicol se indica entre paréntesis en la Fig. 6. La concentración de $0,6 \mathrm{mg} / \mathrm{mL}$ tiene el mayor número de adultos alterados morfológicamente, con 4 individuos en total (Fig. 6).

El ritmo en los ciclos de vida de Drosophila melanogaster no se modificó en concentraciones de 0,3, 0,6, 0,8 y 1,2 $\mathrm{mg} / \mathrm{mL}$ de oxitetraciclina, sin embargo, a concentraciones mayores a estas $(1,6$ y $3,2 \mathrm{mg} / \mathrm{mL})$ hubo retraso significativo para alcanzar el estado adulto en Drosophila melanogaster (Fig.7).

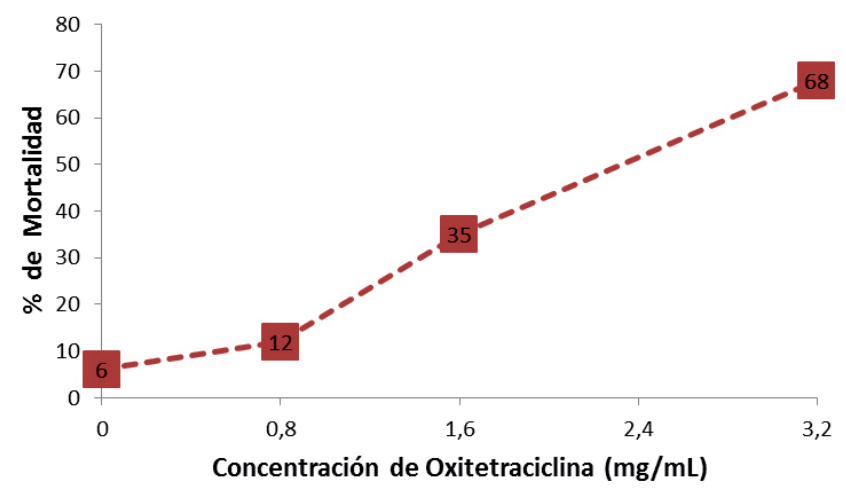

Figura 4. Porcentaje de mortalidad de individuos adultos en el grupo parental de D. melanogaster en 3 concentraciones de oxitetraciclina. / Percentage of mortality of adult individuals in the parental group of $D$. melanogaster in 3 concentrations of oxytetracycline.

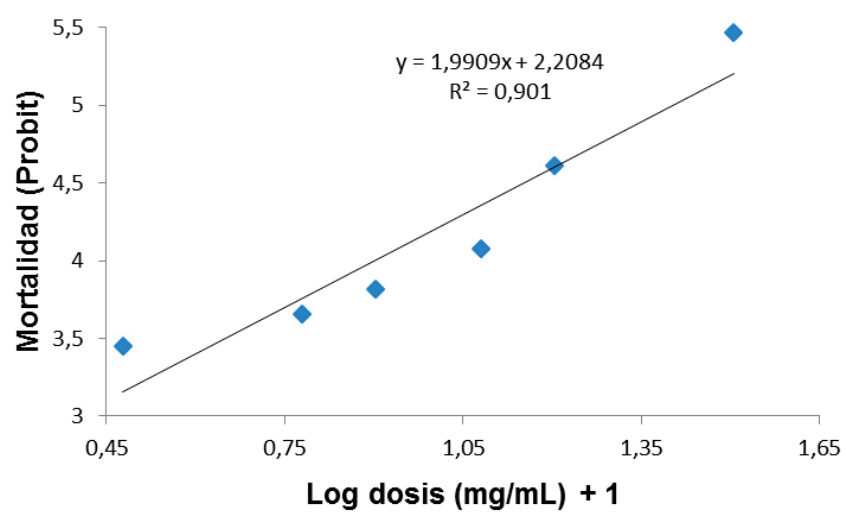

Figura 5. Línea dosis-Probit (Ldp) para oxitetraciclina evaluados en el control de larvas D. melanogaster en laboratorio. / Line doseProbit (Ldp) for oxytetracycline evaluated in the control of larvae D. melanogaster in laboratory. 


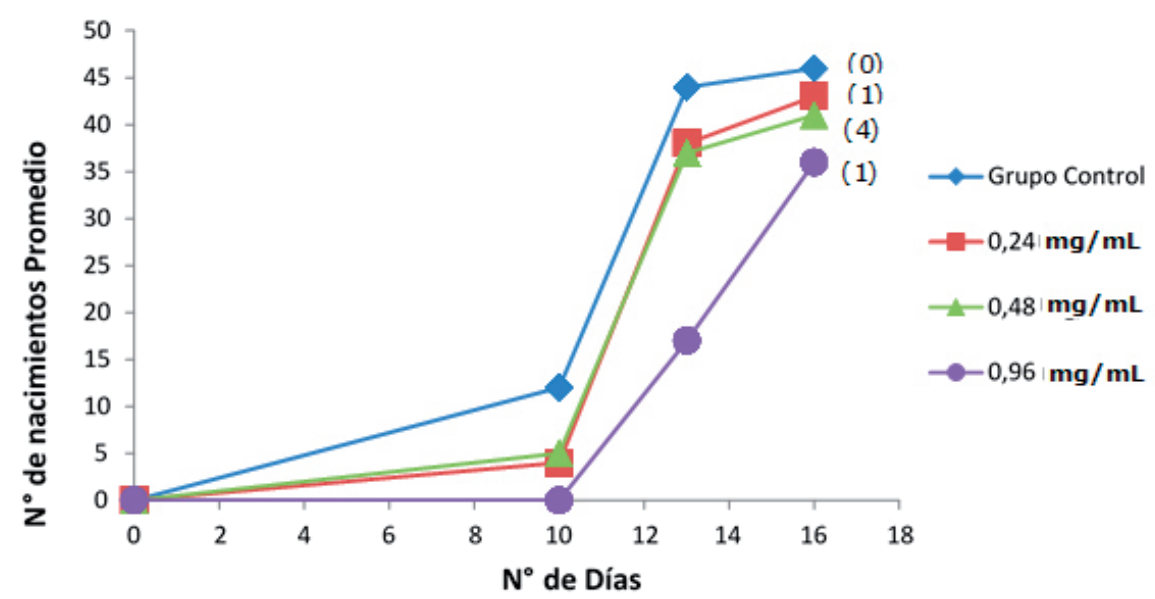

FIgURA 6. Número promedio de nacimientos por día (a partir del décimo dia) para las distintas concentraciones de florfenicol evaluadas en D. melanogaster. Entre paréntesis: número de mutantes observados. / Average number of births per day (from the tenth day) for the different concentrations of florfenicol evaluated in D. melanogaster. In parentheses: number of mutants observed.

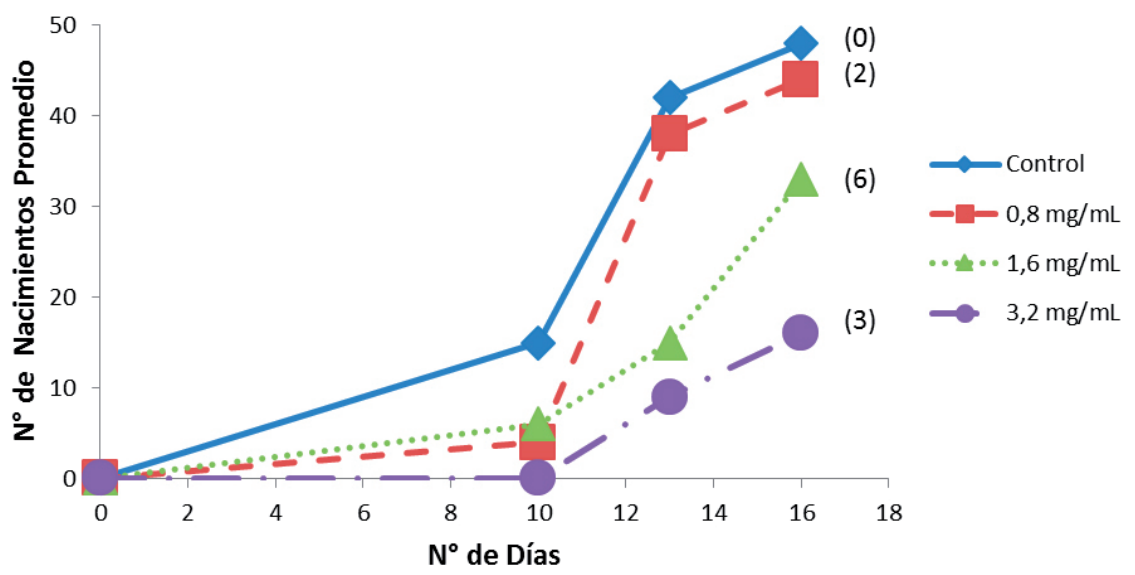

FiguRa 7. Número promedio de nacimientos por día (a partir del décimo día) para las distintas concentraciones de oxitetraciclina evaluadas en D. melanogaster. Entre paréntesis: número de mutantes observados. / Average number of births per day (from the tenth day) for different concentrations of oxytetracycline evaluated in D. melanogaster. In parentheses: number of mutants observed.

NATALIDAD DE LA PRIMERA Y SEGUNDA GENERACIÓN FILIAL

En la primera generación, la tasa de natalidad no fue afectada por florfenicol, mientras que la segunda generación, la tasa de natalidad disminuye conforme aumenta la concentración del antibiótico, no superando los 200 individuos por tratamiento. Se indica en el gráfico (Fig. 8a) el número de individuos mutantes observados en cada concentración, donde la mayor cantidad se concentra en $\operatorname{los} 0,6 \mathrm{mg} / \mathrm{mL}$, al igual que en el grupo parental (Fig. 8a).

En la primera como en la segunda generación filial, el tratamiento con oxitetraciclina, la tasa de natalidad disminuye conforme aumentan las concentraciones, alcanzándose un máximo de 280 individuos totales en la concentración más baja $(0,8 \mathrm{mg} / \mathrm{mL})$, comparados con 780 individuos contabilizados en el grupo control (Fig. 8b).
Morfología Externa de larvas E INDividuos ADULTOS AFECTADOS

Los antibióticos florfenicol y oxitetraciclina generaron cambios morfológicos significativos en larvas e individuos adultos. Las larvas del grupo control presentaron color blanco, segmentos definidos y región cefálica normal (Fig. 9a). Las larvas de los tratamientos con antibióticos manifestaron distensión total del cuerpo, disminución de volumen (Fig. 9b), oscurecimiento de cutícula, la cual se tornó de color beige en la parte anterior y café, en la porción media y posterior (Fig. 9c). Los adultos del grupo control presentaron ojos redondos y de color rojo; cuerpo normal, de color castaño oscuro; alas transparentes, ligeramente puntiagudas y que sobrepasaban la longitud del abdomen (Fig. 10a). Los adultos afectados en los tratamientos con 
antibiótico mostraron daño morfológico, principalmente a nivel del ala, la que no alcanzaba a completarse (Fig. 10b, 10c, 10d) o bien no estaba presente en los individuos (Fig. $10 \mathrm{e}, 10 \mathrm{f}, 10 \mathrm{~g})$. Un número importante de organismos al final de cada tratamiento, era de tamaño más pequeño que los del grupo control. No se hicieron medidas de esta observación.

AnÁlisis del Sustrato: Pruebas de Susceptibilidad POR Difusión EN AGAR Posteriores AL BIOENSAYO

Las pruebas de susceptibilidad por difusión en agar, realizados 30 días después de iniciados los tratamientos, indicaron presencia del antibiótico florfenicol en los medios de cultivo, dando positivo en la cepa E. coli SI, pero no en la cepa $E$. coli $\mathrm{K}-12$, donde no hubo halos de inhibición en ninguna concentración ensayada (Fig. 11). El medio de cultivo en presencia de oxitetraciclina tenía una consistencia muy alterada y la concentración usada en los bioensayos era demasiado alta para medir halos de inhibición, sin embargo su actividad inhibitoria sobre las placas era evidente, no había crecimiento bacteriano, lo que evidenciaba la actividad del antibiótico, por lo que suponemos que la oxitetraciclina en el alimento se mantiene hasta al final de los 30 días. En general, esta prueba reveló que los antibióticos se mantienen y además, difunden desde la matriz de agar que lo contiene hacia el alimento.
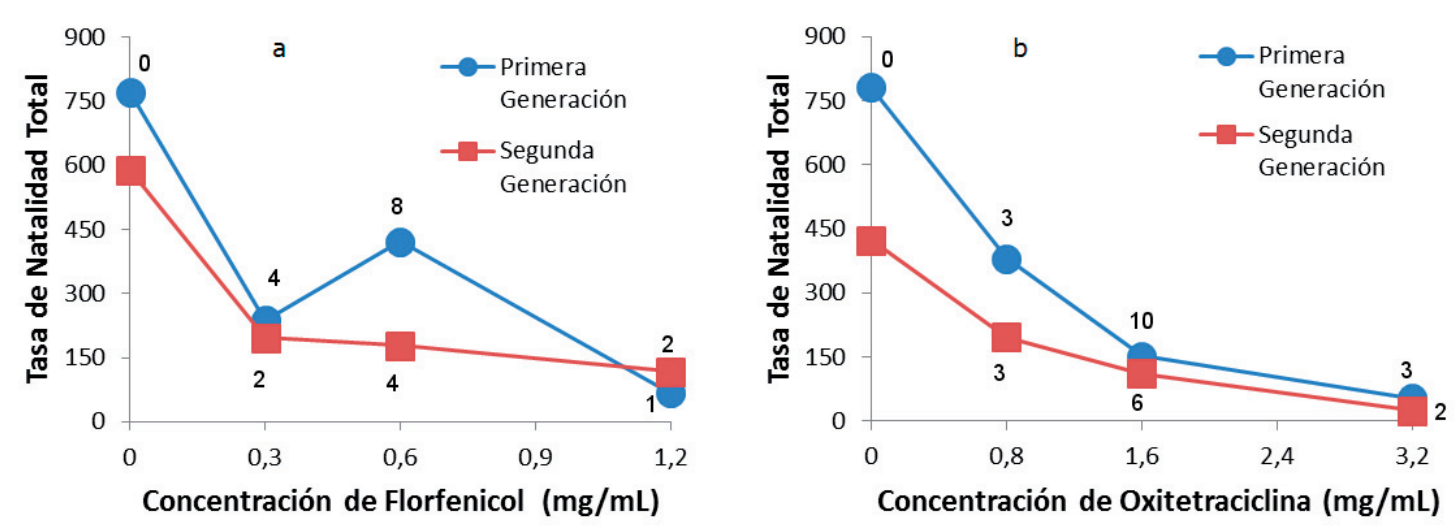

FigURA 8. Tasa de natalidad de la primera y segunda generación filial en concentraciones crecientes de a) florfenicol y b) oxitetraciclina en D. melanogaster. Números indican mutantes observados. / Birth rate of the first and second filial generation in increasing concentrations of a. florfenicol and b. oxytetracycline in D. melanogaster. Number means mutants observed.
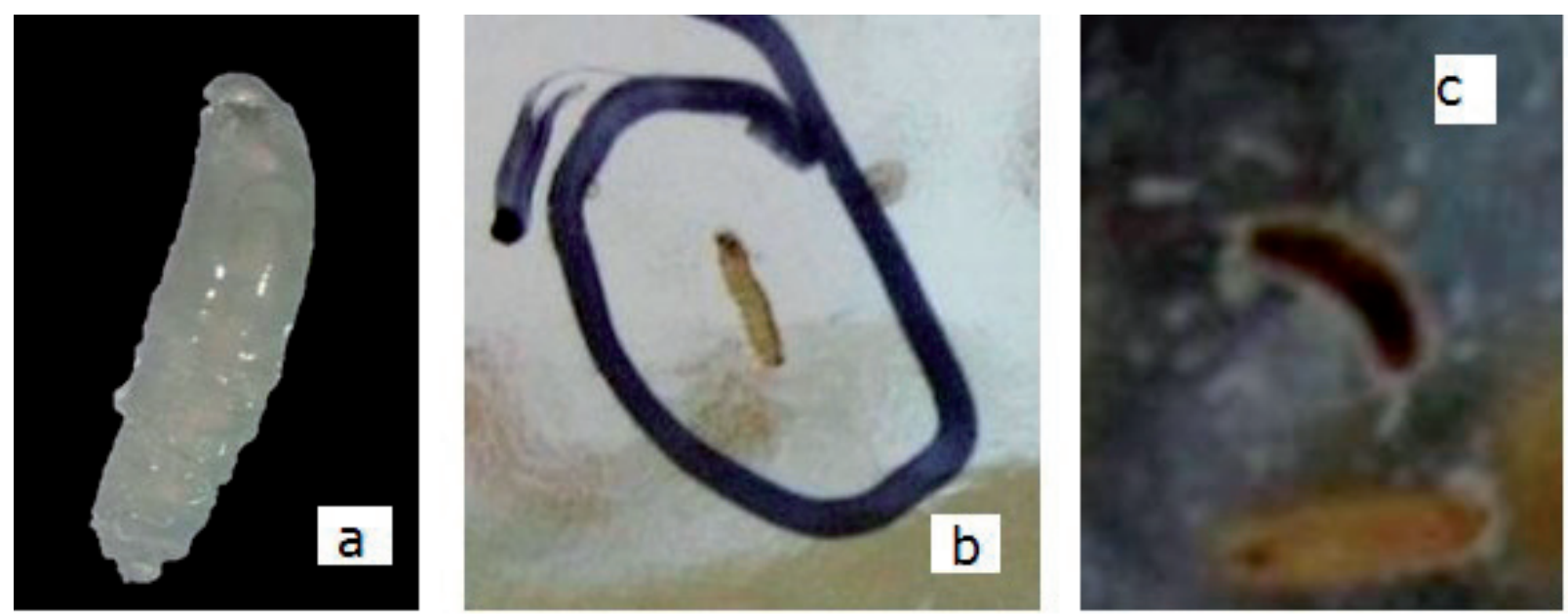

Figura 9. Larvas de Drosophila melanogaster. a) larva control. b-c) larvas sometidas a tratamiento. / Larvae of Drosophila melanogaster. a) larva control. b-c) larva subjected to treatment. 

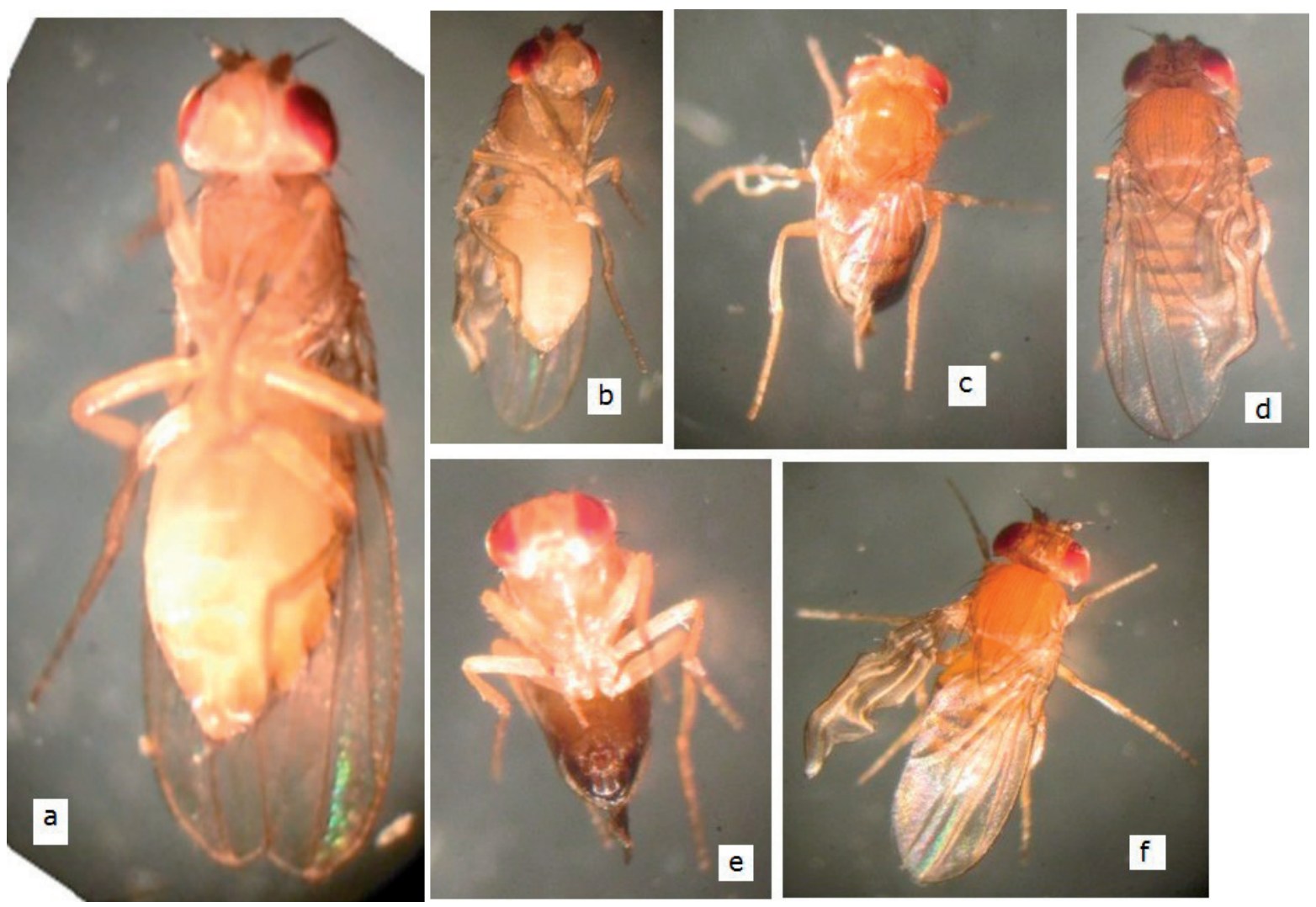

Figura 10. Adultos de Drosophila melanogaster. a) adulto control. b-f) adultos sometidos a tratamiento. / Adults of Drosophila melanogaster. a) adult control. b-f) adults under treatment.

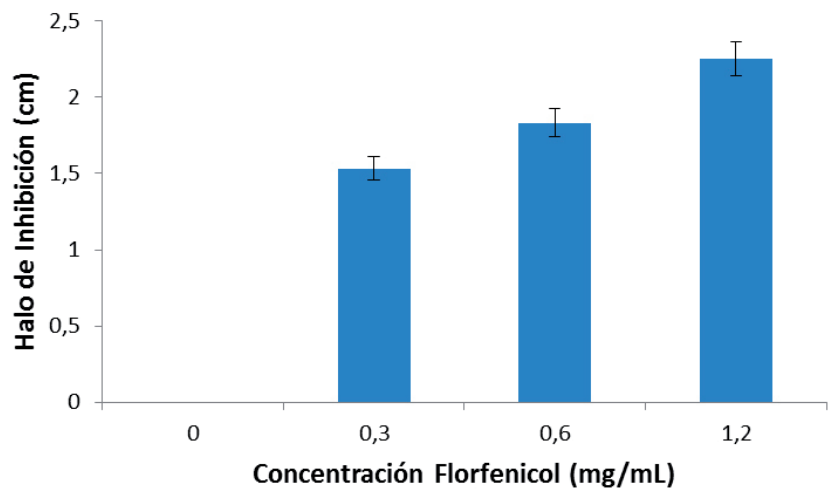

FIgURA 11. Representación gráfica de pruebas de susceptibilidad por difusión en agar realizados 30 días después de iniciado el tratamiento con florfenicol, de la mezcla del alimento en el frasco de cultivo de las larvas, usando la cepa bacteriana $E$. coli SI. / Graphic representation of test of susceptibility through agar diffusion, performed 30 days after the beginning of florfenicol treatment, of the food mixture in the larval culture flask, using the bacterial strain E. coli SI.
AsPeCto GENERAL DE FRASCOS Y MEDIO DE CULTIVO AL FINAL DEL EXPERIMENTO

Los frascos de cultivo de los tratamientos con florfenicol y oxitetraciclina, presentaron variaciones de $\mathrm{pH}$ y coloración durante el estudio. El grupo control presentó sustratos de color amarillo oscuro, levemente humectado al cabo de 7 días y cuyo $\mathrm{pH}$ oscilaba entre los 6,0-6,5. Los tratamientos, en cambio, presentaron un sustrato cuya coloración variaba del café claro (Fig. 12a) al café oscuro (Fig. 12b), dependiendo de la concentración de antibiótico en el medio; superficie seca y un pH que oscilaba entre 6,5-8,0 (también dependiente de la concentración de antibiótico en el medio). Las pupas del grupo control se encontraban distribuidas por todo el frasco de vidrio, alejadas del alimento y en un número alto de individuos. Las pupas de los tratamientos, se distribuían sobre el alimento y unas pocas entraban en contacto con el vidrio del frasco, además el número de ejemplares era considerablemente menor que las observadas en el grupo control (Fig. 13). 

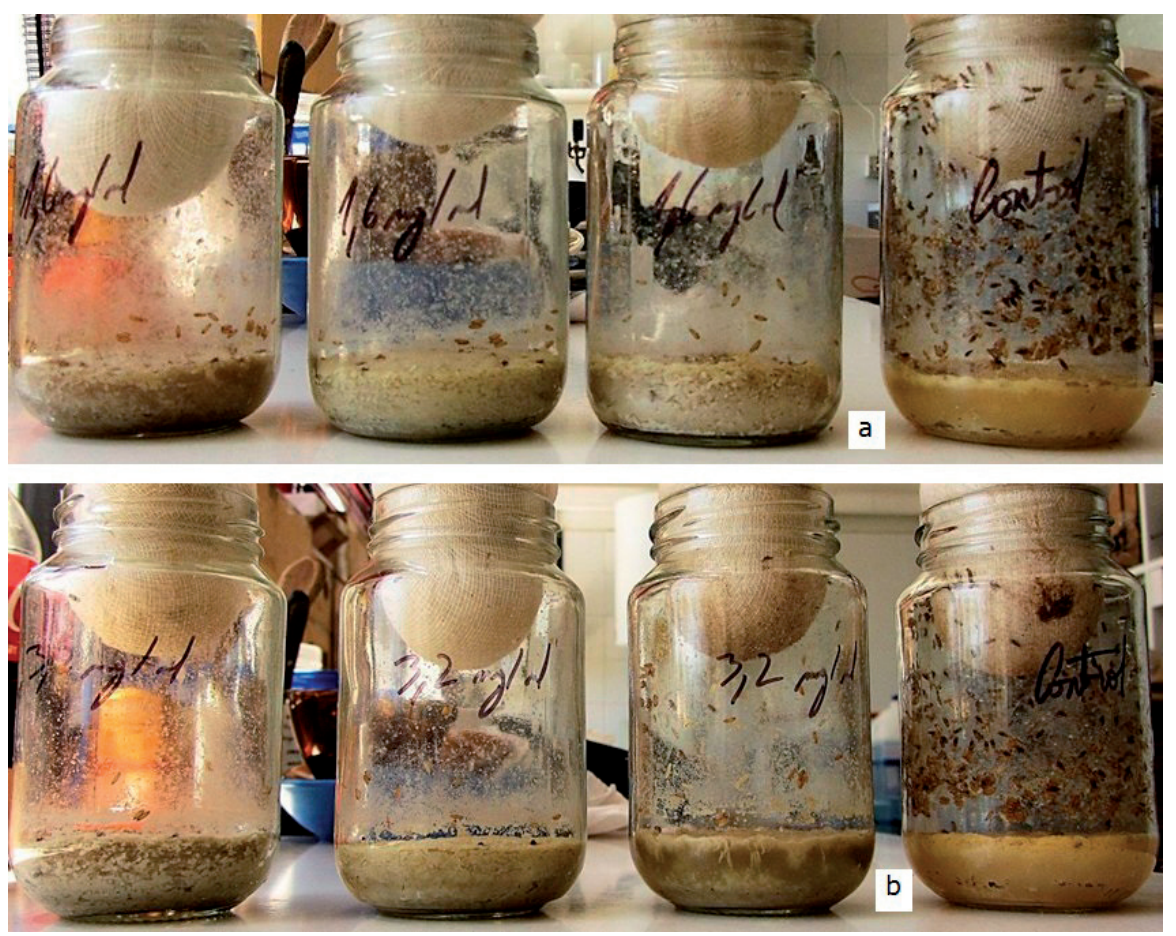

Figura 12. Comparación entre el control y los tratamientos con oxitetraciclina de medios de cultivo en Drosophila melanogaster. a) 1,6 $\mathrm{mg} / \mathrm{mL}$. b) $3,2 \mathrm{mg} / \mathrm{mL}$. / Comparison between control and oxytetracycline treatments of culture media in Drosophila melanogaster. a) 1.6 $\mathrm{mg} / \mathrm{mL}$. b) $3.2 \mathrm{mg} / \mathrm{mL}$.

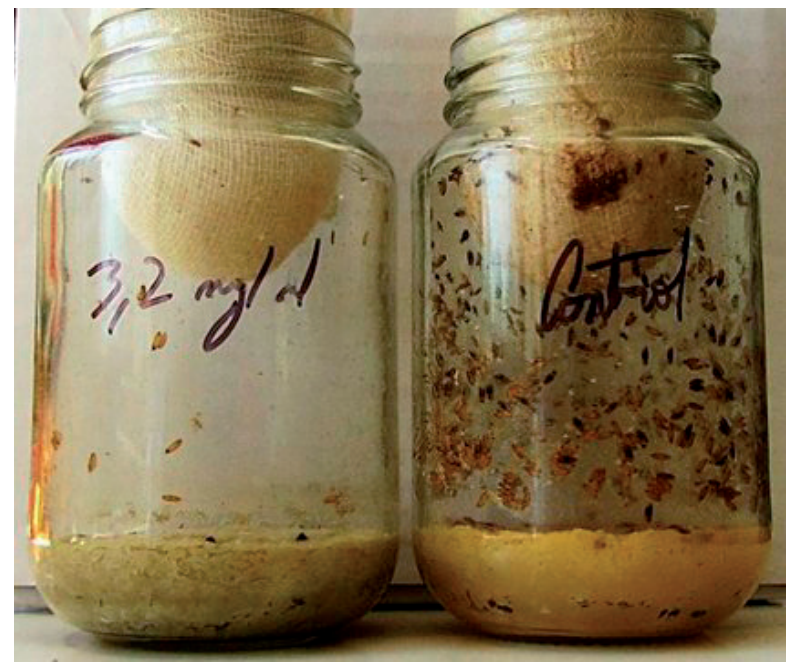

FIGURA 13. Comparación entre tratamientos (izquierda) el grupo control (derecha) del número de pupas de Drosophila melanogaster y su ubicación en los frascos en tratamientos con oxitetraciclina $(3,2 \mathrm{mg} / \mathrm{mL})$. / Comparison between treatments (left) the control group (right) of the number of pupae of Drosophila melanogaster and their location in the bottles in treatments with oxytetracycline $(3.2 \mathrm{mg} / \mathrm{mL})$.

\section{DISCUSIÓN}

La mayor parte de los bioensayos estandarizados, evalúa el efecto antibiótico en corto plazo, en una sola generación, calculando el índice de mortalidad o inhibición del crecimiento de la población en un tiempo definido (72 ó 96 h). Esta investigación, informa sobre el efecto en la descendencia (en dos generaciones sucesivas) donde parentales y descendencia fueron sometidos a la acción de antibióticos en la etapa larval, específicamente estado larva II de la cepa silvestre "santiago" de Drosophila melanogaster. Estudios anteriores realizados con Daphnia magna informaron de efectos trans-generacionales sobre los individuos y las poblaciones de esta especie sometida a la acción de tetraciclinas, en cuatro generaciones sucesivas (Kim et al. 2017, 2014), atribuyendo este efecto transgeneracional a la redistribución del gasto metabólico (Kim et al. 2012).

Los antibióticos embebidos en una matriz de agar al ser aplicados sobre el alimento de larvas de Drosophila melanogaster, en ensayos separados, mostraron distinta actividad biológica y difunden hacia el alimento subyacente probablemente producto del movimiento constante de las larvas. La alimentación de larvas de Drosophila melanogaster con antibióticos, indicó que a igual concentración florfenicol es más letal en la generación parental $(28 \%$ de mortalidad) que oxitetraciclina $(18 \%$ 
de mortalidad) (Fig. 3). Dada la similitud en la estructura química del florfenicol con hormona juvenil, que mantiene el estado larval en el ciclo de vida e interactúa con ecdisonas para cambiar el equilibrio balanceado entre ambas hormonas y producir la metamorfosis (Pastor et al. 2006). Se puede atribuir al florfenicol un efecto disruptor endocrino afectando la progresión del ciclo vital, con mudas tardías o adultos que no emergen de la pupa (Ren et al. 2016; Jindra et al. 2015, 2013; DeFur 2004; Riddiford, \& Ashburner 1991; Viñuela et al. 1991). La exposición a concentraciones excesivas de hormona juvenil en la etapa larval evita la metamorfosis, no diferenciándose las estructuras del adulto. La eclosión del adulto no necesita hormona juvenil (Riddiford \& Ashburner 1991). En la descendencia de los adultos tratados en la etapa larval con florfenicol también hay un efecto de retardo del ciclo de vida del insecto, en generaciones sucesivas, proporcional a la concentración ensayada del antibiótico sobre las larvas de los parentales (Fig. 6 y Fig. 7). No se observa cambio en el ritmo del ciclo de vida del insecto en la descendencia en las mismas concentraciones de oxitetraciclina en los parentales de la primera generación.

Se estimó la $\mathrm{CL}_{50}$ para florfenicol con un valor de 2,6 $\mathrm{mg} / \mathrm{mL}$ en la línea dosis-Probit (Fig. 5). A una concentración de $3,2 \mathrm{mg} / \mathrm{mL}$ la mortalidad de Drosophila melanogaster es de un $68 \%$. El florfenicol afecta a nivel de la síntesis de proteínas a organelos de origen procariótico de la célula eucariótica (mitocondria y cloroplasto). Causa alteraciones estructurales graves, disfunción de mitocondrias, y como consecuencia, inhibe la proliferación celular por acumulación de daños en mitocondrias, causa un aumento de la senescencia celular en cultivos de fibroblastos de ratón (Hu et al. 2017). El efecto tóxico de florfenicol sobre el cloroplasto, produce inhibición del crecimiento de cultivos de microalgas (Chlorella pyrenoidosa, Isochrysis galbana y Tetraselmis chui) (Wang et al. 2015; Du \& Liu 2012; Lai et al. 2009), inhibiendo la fotosíntesis en Skeletonema costatum, a una concentración mayor o igual a $1 \mathrm{mg} / \mathrm{L}$ en 6 h (Liu et al. 2012).

Para el bioensayo con oxitetraciclina en Drosophila melanogaster, se estimó un valor de $\mathrm{CL}_{50}(2,6 \mathrm{mg} / \mathrm{mL})$. En este trabajo fue ensayado el valor equivalente a la concentración de antibiótico recomendado para peces y utilizado en salmonicultura en nuestro país. Este valor es mil veces superior al informado en la literatura para otras especies. Por ejemplo, Lützøft et al. (1999) encontraron que a las $72 \mathrm{~h}$ la $\mathrm{CL}_{50}$ de oxitetraciclina era de $1,6 \mathrm{mg} / \mathrm{L}$ para el alga de agua dulce Raphidocelis subcapitata y de 4,5 $\mathrm{mg} / \mathrm{L}$ para el alga Rhodomonas salina. A su vez, Ferrreira et al. (2007), informaron que la $\mathrm{CL}_{50}$ determinada para la microalga Tetraselmis chuii fue de $11,18 \mathrm{mg} / \mathrm{L}$. Estas diferencias también podrían ser atribuidas a la matriz que contiene al antibiótico (agua dulce versus matriz de agar en este estudio) que pudiera afectar la disponibilidad o la biodisponibilidad del antibiótico. Al comparar con el crustáceo Artemia parthenogenetica (3 $\mathrm{mm}$ de longitud (similar al tamaño de Drosophila melanogaster), el valor de $\mathrm{CL}_{50}$ asciende a $870,47 \mathrm{mg} / \mathrm{L}$ (Ferreira et al. 2007), por lo que es probable que los artrópodos sean más resistentes a la acción de los antibióticos que las microalgas y se necesita mayor concentración de los antibióticos para producir un efecto medible en artrópodos.

Nuestros resultados evidencian un daño morfológico y del ciclo de vida en Drosophila melanogaster. La oxitetraciclina produce mortalidad superior al $65 \%$ en el grupo parental, y en las generaciones sucesivas, menor natalidad, en directa relación con las concentraciones aplicadas. El número de mutantes observados es mayor en los tratamientos con oxitetraciclina que en aquellos donde se utilizó florfenicol. A igual concentración, el antibiótico florfenicol es más letal que oxitetraciclina, en el grupo parental de Drosophila melanogaster. En experimentos de exposición multigeneracional de Dafnia magna en 4 generaciones, a tetraciclinas, aplicados por 21 días en cada generación han demostrado que hay efectos negativos sobre la reproducción en todas las generaciones y aumentado en las sucesivas generaciones, disminuyendo la tasa de crecimiento intrínseca de la población atribuyéndose al gasto energético metabólico en detrimento de la reproducción (Kim et al. 2014, 2012).

La tasa de natalidad en la primera y segunda generación filial disminuye, en comparación con el grupo control, en tres generaciones sucesivas de Drosophila melanogaster. A mayor concentración del antibiótico usada sobre la generación parental y sobre las generaciones sucesivas, mayor es el efecto en las generaciones sucesivas. Esto se manifiesta en una disminución de descendientes o aparición de un mayor número de individuos con moscas adultas que presentan deformaciones del ala, en bajo porcentaje, lo que implicaría posibilidad de daño del material genético heredable inducido antibióticos ingeridos en la etapa larvaria. Estos antibióticos afectarían directamente a los discos imaginales del ala que están presentes en la larva (Wolpert et al. 2007). Los cambios morfológicos del insecto atribuibles a la acción de los antibióticos ensayados se expresa en el ala, que en algunos casos estaba ausente o incompleta (Fig. 10b-g), implicaría que en el estado II de la larva, el antibiótico actuaría sobre las células de los discos imaginales del ala, antes que el disco imaginal se haga competente para metamorfosear al final del estadio II de la larva (Riddiford \& Ashburner 1991). La disminución del número de individuos de una generación a otra también puede ser atribuido al comportamiento del macho durante el cortejo, que incluye una serie de actos ejecutados en el vuelo, antes de copular (Siegel \& Hall 1979; Spieth 1974). O'Shea \& Singh (2015) demostraron que la tetraciclina afecta la aptitud reproductiva de Drosophila melanogaster y la proporción sexual de la descendencia de machos y hembras 
tratados separadamente con el antibiótico. Los machos tratados con el antibiótico, cruzados con hembras no tratadas producen exceso de machos en la descendencia y reducción de la aptitud reproductiva del macho, lo que se manifiesta en una condición de movilidad espermática reducida en padres y heredada por sus hijos en Drosophila melanogaster (Zeh et al. 2012; Yang \& Lu 2011) también demostrada en vertebrados, incluyendo al hombre (Elzeinova et al. 2013; Hargreaves et al. 1998). Efectos multigeneracionales de oxitetraciclina sobre Daphnia magna demostraron que induce diferentes respuestas transcripcionales dependientes de las dosis aplicadas y la generación considerada lo que afecta al metabolismo (Kim et al. 2017).

En concordancia con lo anterior, Botelho et al. (2015) demostraron efectos negativos de florfenicol y oxitetraciclina sobre juveniles del pez Oreochromis niloticus, usando el ensayo del cometa se demostró daño en el ADN de los eritrocitos del pez, y además, un alto porcentaje de deformidades citológicas evidenciando efecto sobre el material genético presentando núcleo con escotadura, lobulado y fragmentado. No ha sido explicada a nivel molecular la toxicidad de florfenicol sobre el material genético. La genotoxicidad de la oxitetraciclina se debe a la fuerte afinidad de tetraciclinas al ADN, formando complejos binarios que alteran la estructura secundaria del ADN nativo (Khan \& Musarrat 2003). Ballard \& Melvin (2007) comprobaron efecto de tetraciclinas en el metabolismo mitocondrial en dos generaciones de Drosophila melanogaster. Oliveira et al. (2013) demostraron que concentraciones de exposición sobre $50 \mathrm{mg} / \mathrm{L}$ de oxitetraciclina causa disminución de la actividad antioxidante de la catalasa del pez adulto Danio rerio y aumento de la actividad de la glutathion S-transferasa muscular y hepática en concentraciones superiores a $10 \mathrm{mg} / \mathrm{L}$. Efectos adversos de tetraciclinas a células eucariontes incluyen una marcada reducción y retraso del crecimiento, reducción del consumo de oxígeno, reducción en la fecundidad en varias especies, incluyendo a Drosophila melanogaster (Moullan et al. 2015; Zeh, et al. 2012; Çelik \& Eke 2011).

Kołodziejska et al. (2013) investigó la toxicidad de florfenicol y oxitetraciclina en una microalga (Scenedesmus vacuolatus), en la planta acuática, "lenteja de agua" (Lemna minor) y un crustaceo (Daphnia magna), demostrando un efecto notable de cada antibiótico, sobre la lenteja de agua como lo evidencia el valor de las concentraciones de exposición a florfenicol $\left(\mathrm{EC}_{50}=3.26 \mathrm{mg} / \mathrm{L}\right)$ y a oxitetraciclina $\left(\mathrm{EC}_{50}=2.96 \mathrm{mg} / \mathrm{L}\right)$, y sobre la microalga, con $\mathrm{EC}_{50}=40.4 \mathrm{mg} / \mathrm{L}$ para florfenicol y $\mathrm{EC}_{50}=18.0 \mathrm{mg} / \mathrm{L}$, para oxitetracilina.

En acuicultura el $70-80 \%$ de los antimicrobianos se distribuye por corrientes marinas y remolinos o por movimientos del agua causados por la biota marina (Monteiro et al. 2016). Oxitetraciclina puede permanecer biológicamente activa en los sedimentos durante meses e inclusive años (Coyne et al. 1997; Capone et al. 1996). La vida media de este compuesto en la capa superior de los sedimentos marinos $(0-1 \mathrm{~cm})$, es de 151 días, a profundidades de $5-7 \mathrm{~cm}$, la vida media se extiende a 300 días (Hektoen et al. 1995). Las pruebas de susceptibilidad por difusión en agar del antibiótico contenido en la matriz de agar realizados 30 días después de iniciado los tratamientos indican presencia de florfenicol en el sustrato usado por la mosca para alimentarse (Fig. 11), mostrando la misma potencia inhibitoria. Este mismo análisis no pudo ser medido en el medio de cultivo con oxitetraciclina. En nuestro experimento, el medio de cultivo con oxitetraciclina se oscureció a tonos marrones por fotodegradación (Pouliquen et al. 2007), también observado por otros autores tras $24 \mathrm{~h}$ de exposición de este antibiótico en agua, cuyos productos presentarían actividad antibiótica (Botelho et al. 2015; Ferreira et al. 2007).

El florfenicol, tiene alta afinidad por sustancias hidrofóbicas (lípidos y grasas) a diferencia de oxitetraciclina, que es hidrosoluble (Hektoen et al. 1995) y menos persistente en el medio acuático (Elema et al. 1996). Por lo tanto, la acumulación de materia orgánica bajo las jaulas de salmones, podría retener antibióticos, dependiendo de la granulometría del fondo y contenido de arcillas, lo que es un grave factor de riesgo para la natural bentónica. En sedimentos marinos la permanencia del florfenicol es breve, porque la microflora presente en el fondo lo degrada (Hektoen et al. 1995) pero en ambientes donde constantemente se están liberando antibióticos al medio, la microbiota se reduce, aumentando la persistencia del antibiótico, como se observó en el medio estéril de cultivo de larvas de Drosophila melanogaster en este trabajo. En el tiempo de vida medio equivalente a 4-5 días, se puede transformar a un derivado florfenicol amina, más persistente (Hektoen et al. 1995) o permanecer asociado a la materia orgánica del sedimento del fondo marino (Yu et al. 2011). El tiempo de vida media del florfenicol en el tramo entre 0 a $1 \mathrm{~cm}$ es de 1,7 días, en tanto, a 5-7 cm de profundidad es de 7,3 días (Hektoen et al. 1995).

Con la información obtenida de este estudio es necesario con fines de conservación del entorno inmediato de las salmonicultura, se recomienda evaluar el efecto específico de estos antibióticos, usando organismos propios de la fauna natural que circunda alrededor de los centros de cultivo de salmón, analizando ciclos de vida y mortalidad en los individuos, donde se incluya un número consistente de generaciones, que permitan comprender el efecto de estos y otros antibióticos en el tiempo.

\section{REFERENCIAS}

Araya, I., Prat, S., Ramirez, V. 2002. Prueba de susceptibilidad antimicrobiana por difusión en agar. Instituto de Salud 
Pública. Chile. National Committee for Clinical Laboratory Standard (NCCLS): 1-17.

Artigas, J. 1998. Entomología económica: insectos de interés agrícola, forestal, médico y veterinario (nativos, introducidos y susceptibles de ser introducidos). Vol. I. Ediciones Universidad de Concepción. Concepción, Chile.

Baguer, A., Jensen, J., Krogh, P. 2000. Effects of the antibiotics oxytetracycline and tylosin on soil fauna. Chemosphere 40 (7): 751-757.

Barrientos, M. 2006. Estudio cualitativo y cuantitativo de las quinolonas y fluoroquinolonas importadas y autorizadas para uso y disposición en medicina y en veterinaria en Chile, en el período 2002-2005. Consideraciones sobre su impacto para la salud pública y el medio ambiente. Valdivia, Chile: Universidad Austral de Chile. URL:http:// cybertesis.uach.cl/tesis/uach/2006/fcb2751e/doc/ fcb2751e.pdf.

Barton, J., Floysand, A. 2010. The political ecology of Chilean salmon aquaculture, 1982-2010: a trajectory from economic development to global sustainability. Global Environmental Change 20: 739-752.

Ballard, J. W. O., Melvin, R. G. 2007. Tetracycline treatment influences mitochondrial metabolism and mtDNA density two generations after treatment in Drosophila. Insect Molecular Biology 16(6): 799-802.

Botelho, R. G., Christofoletti, C. A., Correia, J. E., Ansoar, Y., Olinda, R. A., Tornisielo, V. L. 2015. Genotoxic responses of juvenile tilapia (Oreochromis niloticus) exposed to florfenicol and oxytetracycline. Chemosphere 132: 206212.

Boxall, A., Fogg, L., Blackwell, P., Kay, P., Pemberton, E., Croxford, A. 2004. Veterinary medicines in the environment. Reviews of Environmental Contamination and Toxicology 180: 1-91.

Burka, J., Hammell, K., Horsberg, T., Johnson, G., Rainnie, D., Speare, D. 1997. Drugs in salmonid aquaculture - a review. Journal of Veterinary Pharmacology and Therapeutics 20: 333-349.

Burridge, L., Weis, J., Cabello, F., Pizarro, J., Bostick, K. 2010. Chemical use in salmon aquaculture: a review of current practices and possible environmental effects. Aquaculture 306: 7-23.

Buschmann, A.H., Riquelme, V.A., Hernández-González, M. C., Varela, D., Jiménez, J.E., Henríquez, L., Vergara, P., Guíñez, R., Filún, L. 2006. A review of the impacts of salmonid farming on marine coastal ecosystems in the southeast Pacific. ICES Journal of Marine Science 63(7): 1338-1345.

Buschmann, A., Cabello, F., Young, K., Carvajal, J., Varela, D., Henríquez, L. 2009. Salmon aquaculture and coastal ecosystem health in Chile: analysis of regulations, environmental impacts and bioremediation systems. Ocean \& Coastal Management 52: 243-249.

Buschmann, A., Tomova, A., López, A., Maldonado, M., Henríquez, L., Ivanova, L., Godfrey, H., Cabello, F. 2012. Salmon aquaculture and antimicrobial resistance in the marine environment. PLoS ONE 7(8): e42724. doi:10.1371/journal.pone.0042724.

CABello, F. 2003. Antibióticos y acuicultura: un análisis de sus potenciales impactos para el medio ambiente, la salud humana y animal en Chile. Análisis de Políticas Públicas. Organización Terram, Publicación No 17.

Cabello, F. 2006. Heavy use of prophylactic antibiotics in aquaculture: a growing problem for human and animal health and for the environment. Environmental Microbiology 8:1137-1144.

Capone, D., Weston, D., Miller, V., Shoemaker, C. 1996. Antibacterial residues in marine sediments and invertebrates following chemotherapy in aquaculture. Aquaculture 145: 55-75.

Çelik, A., Eke D. 2011. The assessment of cytotoxicity and genotoxicity of tetracycline antibiotic in human blood lymphocytes using $\mathrm{CBMN}$ and SCE analysis, in vitro. International Journal of Human Genetics 11(1): 23-29.

Christensen, A.M., Ingerslev, F., Baun, A. 2006. Ecotoxicity of mixtures of antibiotics used in aquacultures. Environmental Toxicology and Chemistry 25: 2208-2215.

Coyne, R., Hiney, M., Smith, P. 1997. Transient presence of oxytetracycline in blue mussels (Mytilus edulis) following its therapeutic use at a marine Atlantic salmon farm. Aquaculture 149:175-181.

DeBach, P. 1968. Control biológico de las plagas de insectos y malas hierbas. Continental. México D.F., México.

Defur, P. 2004. Use and role of invertebrate models in endocrine disruptor research and testing. Institute for Animal Research Journal 45: 484-493.

Demerec, M., Kaufmann, B. 1969. Drosophila guide: introduction to the genetics and cytology of Drosophila melanogaster. Carnegie Institution of Washington. Washington D.C., USA.

Di Rienzo J.A., Casanoves F., Balzarini M.G., Gonzalez L., Tablada M., Robledo C.W. InfoStat versión 2015. Grupo InfoStat, FCA, Universidad Nacional de Córdoba, Argentina. URL:http://www.infostat.com.ar

Dölz, H. 2001. Antibióticos en Acuicultura y su impacto en la Salud Pública y el medio ambiente. En Taller de Biotecnología Marina. Universidad Católica de Valparaíso. La Serena.

Du, L., Liu, W. 2012. Occurrence, fate, and ecotoxicity of antibiotics in agro-ecosystems. A review. Agronomy for Sustainable Development 32(2), 309-327.

Elema, M., Hoff, K., Kristensen, H. 1996. Bioavailability of oxytetracycline from medicated feed administered to Atlantic salmon (Salmo salar L.) in seawater. Aquaculture 143: 7-14.

ElzeinovÁ, F., PĚknicová, J., Děd, L., KubátovÁ, A., Margaryan, H., Dorosh, A. Makovicky, P., Rajmon, R. 2013. Adverse effect of tetracycline and doxycycline on testicular tissue and sperm parameters in CD1 outbred mice. Experimental and Toxicologic Pathology 65(6): 911-917.

FAO: Food and Agriculture Organization of the United Nations. 2010. www.fao.org/fishery/aquaculture/en.

FInLAND, M. 1960. Antibacterial agents: Uses and abuses in treatment and prophylaxis. Rhode Island Medical Journal 43:499-520.

Fortt, A., Cabello, F., Buschmann, A. 2007. Residuos de tetraciclina y quinolonas en peces silvestres en una zona costera donde se desarrolla la acuicultura del salmón en Chile. Revista Chilena de Infectología 24:14-18.

Ferreira, C., Nunes, B., Henriques-Almeida, J., Guilhermino, L. 2007. Acute toxicity of oxytetracycline and florfenicol 
Efectos adversos de antibióticos en Drosophila melanogaster: BENAVIDES, O. ET AL.

to the microalgae Tetraselmis chuii and to the crustacean Artemia parthenogenetica. Ecotoxicology and Environmental Safety 67:452-458.

FinNEY, D. J. 1952. Statistical method in biological assay. Charles Griffin: London.

Finney, D., Stevens, W. 1948. A table for the calculation of working probits and weights in probit analysis. Biometrika 35(1-2):191-201.

Fong, C., Díaz, F., Osorio, J., Castano, L., González, F., Jurado, L., Castillo, K., Cárdenas, H. 2008. Efecto de la densidad poblacional de huevos sobre viabilidad y tiempo de desarrollo de Drosophila melanogaster (Drosophilidae). Acta Biológica Colombiana 13(2):123-132.

Fortt, A., Cabello, F., Buschmann, A. 2007. Residuos de tetraciclina y quinolonas en peces silvestres en una zona costera donde se desarrolla la acuicultura del salmón en Chile. Revista Chilena de Infectología 24(1): 14-18.

Godoy-Herrera, R. 2001. La conducta de larvas de Drosophila (Diptera; Drosophilidae): su etología, desarrollo, genética y evolución. Revista Chilena de Historia Natural 74(1): 55-64.

GómEz, C. 2009. Estudio cualitativo y cuantitativo de las tetraciclinas y fenicoles importadas y autorizadas para uso y disposición en medicina y en veterinaria en Chile, en el período 2002-2005. Consideraciones sobre su impacto para la salud pública y el medio ambiente. Valdivia, Chile: Tesis de Grado, Escuela de Química y Farmacia, Universidad Austral de Chile. URL:http://cybertesis.uach. cl/tesis/uach/2009/fcg633e/doc/fcg633e.pdf.

González, M., Gonzalo, S., Rodea, I., Leganés, F., Rosal, R., Boltes, K., Marco, E., Fernández, F. 2013. Toxicity of five antibiotics and their mixtures towards photosynthetic aquatic organisms: Implications for Environmental Risk Assessment. Water Research 47(6): 2050-2064.

Guillén, D., Ginebreda, A., Farré, M., Darbra, R. M., Petrovic, M., Gros, M., BArceló, D. 2012. Prioritization of chemicals in the aquatic environment based on risk assessment: analytical, modeling and regulatory perspective. Science of the Total Environment 440: 236-252.

Halling-Sørensen, B., Nors, S., Lanzky, P., Ingerslev, F., Holten, H., Jørgensen, S. 1998. Occurrence, fate and effects of pharmaceutical substances in the environment-a review. Chemosphere 36: 357-393.

Halling-Sørensen, B., Lutzhoft, H., Andersen, H., Ingerslev, F. 2000. Environmental risk assessment of antibiotics: comparison of mecillinam, trimethoprim and ciprofloxacin. Journal of Antimicrobial Chemotherapy 46:53-58.

Hargreaves, C.A., Rogers, S., Hills, F., Rahman, F., Howell, R.J., HomA, S.T. 1998. Effects of co-trimoxazole, erythromycin, amoxycillin, tetracycline and chloroquine on sperm function in vitro. Human Reproduction (Oxford, England) 13(7): 1878-1886.

Hektoen, H., Berge, J., Hormazabal, V., Yndestad, M. 1995. Persistence of antibacterial agents in marine sediments. Aquaculture 133: 175-184.

Hirsch, R., Ternes, T., Haberer, K., Kratz, K. 1999. Occurrence of antibiotics in the aquatic environment. Science of the Total Environment 225:109-118.

Hu, D., Cao, S., Zhang, G., Xiao, Y., Liu, S., Shang, Y. 2017. Florfenicol-induced mitochondrial dysfunction suppresses cell proliferation and autophagy in fibroblasts. Scientific Reports 7(1): 13554.

Ibieta, P., Tapia, V., Venegas, C., Hausdorf, M., Takle, H. 2011. Chilean salmon farming on the horizon of sustainability: review of the development of a highly intensive production, the ISA crisis and implemented actions to reconstruct a more sustainable aquaculture industry. In Aquaculture and the Environment - A Shared Destiny. Sladonja, B. (ed.). Rijeka, Croatia: InTech, pp. 215-246.

Jindra, M., Bellés, X., Shinoda, T. 2015. Molecular basis of juvenile hormone signaling. Current Opinion in Insect Science 11:39-46.

Jindra, M., Palli, S.R., Riddiford, L.M. 2013. The juvenile hormone signaling pathway in insect development. Annual Review of Entomology 58: 181-204.

Kerry, J., Coyne, R., Gilroy, D., Hiney, M., Smith, P. 1996. Spatial distribution of oxytetracycline and elevated frequencies of oxytetracycline resistance in sediments beneath a marine salmon farm following oxytetracycline therapy. Aquaculture 145:31-39.

Khan, M.A., Musarrat, J. 2003. Interactions of tetracycline and its derivatives with DNA in vitro in presence of metal ions. International Journal of Biological Macromolecules 33 (1): 49-56.

Kim, H.Y., Asselman, J., Jeong, T.Y., Yu, S., De Schamphelaere, K.A., KIM, S.D. 2017. Multigenerational Effects of the Antibiotic Tetracycline on Transcriptional Responses of Daphnia magna and Its Relationship to Higher Levels of Biological Organizations. Environmental Science, Technology 51(21): 12898-12907.

Kim, Y., Jung, J., Kim, M., Park, J., Boxall, A.B., Choi, K. 2008. Prioritizing veterinary pharmaceuticals for aquatic environment in Korea. Environmental Toxicology and Pharmacology 26 (2): 167-176.

Kim, H.Y., LeE, M.J., Yu, S.H., KIM, S.D. 2012. The individual and population effects of tetracycline on Daphnia magna in multigenerational exposure. Ecotoxicology 21(4): 9931002.

Kim, H.Y., Yu, S., Jeong, T.Y., Kim, S.D. 2014. Relationship between trans-generational effects of tetracycline on Daphnia magna at the physiological and whole organism level. Environmental Pollution 191: 111-118.

Kümmerer, K. 2009. Antibiotics in the aquatic environment -a review- part II. Chemosphere 75(4): 435-441.

KoŁodziejska, M., Maszkowska, J., BiaŁK-Bielińska, A., Steudte, S., Kumirska, J., Stepnowski, P., Stolte, S. 2013. Aquatic toxicity of four veterinary drugs commonly applied in fish farming and animal husbandry. Chemosphere 92 (9): 1253-1259.

Lai, H.T., Hou, J.H., Su, C.I., Chen, C.L. 2009. Effects of chloramphenicol, florfenicol, and thiamphenicol on growth of algae Chlorella pyrenoidosa, Isochrysis galbana, and Tetraselmis chui. Ecotoxicology and Environmental Safety 72 (2): 329-334.

Le, T., Munekage, Y. 2004. Residues of selected antibiotics in water and mud from shrimp ponds in mangrove areas in Viet Nam. Marine Pollution Bulletin 49:922-929.

Le Bris, H., Pouliquen, H. 2004. Experimental study on the bioaccumulation of oxytetracycline and oxolinic acid by the blue mussel (Mytillus edulis). An evaluation 
of its ability to bio-monitor antibiotics in the marine environment. Marine Pollution Bulletin 48: 434-440.

Lillehaug, A., Lunestad, B., Grave, K. 2003. Epidemiology of bacterial diseases in Norwegian aquaculture - a description based on antibiotic prescription data for the ten-year period 1991 to 2000. Diseases of Aquatic Organisms 53:115-125.

Lützøғt, H., Halling-Sørensen, B., Jørgensen, S. 1999. Algal toxicity of antibacterial agents applied in Danish fish farm. Archives of Environmental Contamination and Toxicology 36:1-6.

Markestad, A., Grave, K. 1997. Reduction of antibacterial drug use in Norwegian fish farming due to vaccination. Fish Vaccinol. 90: 365-369.

Migliore, L., Civitareale, C., Brambilla, G., DiDelupis, G. 1997. Toxicity of several important agricultural antibiotics to Artemia. Water Research 31(7):1801-1806.

Millanao, A. 2002. Estudio cualitativo y cuantitativo de las quinolonas y fluoroquinolonas importadas y autorizadas para uso y disposición en medicina y en veterinaria en Chile, en el período 1998-2001. Consideraciones sobre su impacto para la salud pública y el medio ambiente. Valdivia, Chile: Universidad Austral de Chile. URL: http://cybertesis.uach.cl/tesis/uach/2002/fcm645e/doc/ fcm645e.pdf

Millanao, A., Barrientos, H., Gómez, C., Tomova, A., Buschmann, A., Dölz, H., CABello, F. 2011. Uso inadecuado y excesivo de antibióticos: salud pública y salmonicultura en Chile. Revista Medica de Chile 139:107-118.

Miranda, C., Zemelman, R. 2002. Bacterial resistence to oxytetracycline in Chilean salmon farming. Aquaculture 212: 31-47.

MirandA, C. 2012. Antimicrobial resistance associated with salmonid farming. In Antimicrobial Resistance in the Environment. Hoboken, NJ, USA: John Wiley \& Sons. pp. 423-451.

Morejón, M., Salup R., Cue, M. 2003. Actualización en tetraciclinas. Revista Cubana de Farmacia 37(3): 1-1.

Morris, J. 1999. Harmful algal blooms: an emerging public health program with possible links to human stress on the environment. Annual Review of Energy and the Environment 24:367-390.

Moullan, N., Mouchiroud, L., Wang, X., Ryu, D., Williams, E.G., Mottis, A., Jovaisaite, V., Frochaux, M.V., Quiros, P.M., Bart Deplancke, B., Auwerx, J., HoutKooper, R.H., 2015. Tetracyclines disturb mitochondrial function across eukaryotic models: a call for caution in biomedical research. Cell Reports 10(10): 1681-1691.

MuÑoz, O. 2009. Aguas arriba: la transformación socioeconómica del ecosistema Llanquihue-Chiloé, Chile, durante los años 90. Primera edición. Clacso Libros. Buenos Aires, Argentina. $59 \mathrm{pp}$.

Nordmo, R., Varma, K., Sutherland, I., Brokken, E. 1994. Florfenicol in Atlantic salmon, Salmo salar L.: field evaluation of efficacy against furunculosis in Norway. Journal of Fish Diseases 17: 239-244.

O’Shea, K.L., Singh, N.D. 2015. Tetracycline-exposed Drosophila melanogaster males produce fewer offspring but a relative excess of sons. Ecology and Evolution 5(15): 3130-3139.

Park, D., Peterson, C., Zhao, S., Coats, J. 2004. Fumigation toxicity of volatile natural and synthetic cyanohydrins to stores-product pests and activity as soil fumigants. Pest. Management Science 60: 833-838.

Pastor, J., Martín-Blanco, E., García-Bellido, A. 2006. Eversión y cierre de los discos imaginales. Investigación y Ciencia 352: 72-81.

Pelletier, N., Tyedmers, P., Sonesson, U., Scholz, A., Ziegler, F., FlysJo, A. 2009. Not all salmon are created equal: life cycle assessment (LCA) of global salmon farming systems. Environmental Science \& Technology 43:8730-8736.

Pouliquen, H., Delépée, R., Larhantec-Verdier, M., Morvan, M. L., Le BrIs, H. 2007. Comparative hydrolysis and photolysis of four antibacterial agents (oxytetracycline oxolinic acid, flumequine and florfenicol) in deionised water, freshwater and seawater under abiotic conditions. Aquaculture 262 (1): 23-28.

Powell, J. 1997. Progress and prospects in evolutionary biology. The Drosophila model. Oxford University Press, Oxford, United Kingdom. pp. 562.

Reed, L., Siewicki, T., Shah, J. 2004. Pharmacokinetics of oxytetracycline in the white shrimp, Litopenaeus setiferus. Aquaculture 232: 11-28.

Ren, X., PAn, L., WAng, L. 2016. Tissue distribution, elimination of florfenicol and its effect on metabolic enzymes and related genes expression in the white shrimp Litopenaeus vannamei following oral administration. Aquaculture Research 47(5): 1584-1595.

RidDiford, L.M., Ashburner, M. 1991. Effects of juvenile hormone mimics on larval development and metamorphosis of Drosophila melanogaster. General and Comparative Endocrinology 82(2): 172-183.

Rigos, G., Nengas, I., Alexis, M., Troisi, G. 2004. Potential drug (oxytetracycline and oxolinic acid) pollution from Mediterranean sparid fish farms. Aquatic Toxicology 69:281-288.

Salgado, H., Bailey, J., Tiller, R., Ellis, J. 2015. Stakeholder perceptions of the impacts from salmon aquaculture in the Chilean Patagonia. Ocean, Coastal Management 118: 189204.

SAlgado, R. 2005. Análisis del desarrollo de la salmonicultura chilena. Pontificia Universidad Católica de Chile. Santiago, Chile. 13 pp.

SAlmonchile. 2008. Producción mundial de salmón y trucha cultivado. URL:http://www.salmonchile.cl/files/T4Mundial\%201997-2007.pdf

Samuelsen, O., Bergh, Ø. 2004. Efficacy of orally administered florfenicol and oxolinic acid for the treatment of vibriosis in cod (Gadus morhua). Aquaculture 235: 27-35.

San Martin, B., Gallardo, A., Medina, P. 2014. Manual de buenas prácticas en el uso de antimicrobianos y antiparasitarios en la salmonicultura chilena. Farmavet, Universidad de Chile-Sernapesca, 52.

Sapkota, A., Kucharski, M., Burke, J., McKenzie, S., Walker, P., LaWrence, R. 2008. Aquaculture practices and potential human health risks: current knowledge and future priorities. Environment International 34:1215-1226.

Sarmah, A., Meyer, M., Boxall, A. 2006. A global perspective on the use, sales, exposure pathways, occurrence, fate and effects of veterinary antibiotics (VAs) in the environment. Chemosphere 65(5):725-759. 
Efectos adversos de antibióticos en Drosophila melanogaster: BENAVIDES, O. ET AL.

Schering-Plough. 2007. Nuflor ${ }^{\circledR}$, an antibiotic Type A medicated article for swine. Technical Monograph. Schering-Plough Animal Health. http://www.intervetusa.com/binaries/ pigs\%20-\%20pdflib338 tcm130-165752.pdf

SERNAPESCA. 2017. Informe sobre uso de antimicrobianos en la salmonicultura nacional 2014. Servicio Nacional de Pesca. Ministerio de Economía, Fomento y Turismo, Valparaíso, Chile. 13 pp.

Sewell, D., Burnet, B., Connolly, K. 1975. Genetic analysis of larval feeding behaviour in Drosophila melanogaster. Genetical Research 24:163-173.

SHAO, Z. 2001. Aquaculture pharmaceuticals and biologicals: current perspectives and future possibilities. Advanced Drug Delivery Reviews 50:229-243.

Siegel, R.W., Hall, J.C. 1979. Conditioned responses in courtship behavior of normal and mutant Drosophila. Proceedings of the National Academy of Sciences 76 (7): 3430-3434.

Spieth, H.T. 1974. Courtship behavior in Drosophila. Annual Review of Entomology 19(1): 385-405.

Sørum, H. 2006. Antimicrobial drug resistance in fish pathogens. In antimicrobial resistance in bacteria of animal origin. Washington, DC, USA: ASM Press. pp. 213-238.

Soto, D., Norambuena, F. 2004. Evaluation of salmon farming effects on marine systems in the inner seas of southern Chile: a large-scale mensurative experiment. Journal of Applied Ichthyology 20:493-501.
Storer, T., Usinger, R., Stebbins, R., Nybakken, J. 2001. Zoología General. Ediciones Omega S.A. 210 pp.

Strickberger, M.W. (1962). Experiments in genetics with Drosophila. Experiments in genetics with Drosophila.

Suazo, G., González, F., Urbina, A., Pastene, E., SÁez, K., Serri, H., ChÁvez, R. 2012. Actividad insecticida del aceite esencial de Lepechinia chamaedryoides (Balb.) Epling en Drosophila melanogaster. Gayana. Botánica 69 (2): 256266.

Ueno, R., Kinoshita, A., Wakabayashi, J. 2004. Comparative pharmacokinetics of oxytetracycline in eel and its fate in a closed aquatic environment. Aquaculture 235: 53-63.

Viñuela, E., Budia, F., Del Estal, P. 1991. Los insecticidas reguladores del crecimiento y la cutícula. Boletín de Sanidad Vegetal-Plagas 17: 391-400.

Wollenberger, L., Halling-Sørensen, B., Kusk, K. 2000. Acute and chronic toxicity of veterinary antibiotics to Daphnia magna. Chemosphere 40:723-730.

Wolpert, L., Jessell, T., Lawrence, P., Meyerowitz, E., Robertson, E., Smith, J. 2007. Principios del desarrollo. Editorial Médica Panamericana. 3a. edición. 553 pp.

YANG, Y., Lu, X. 2011. Drosophila sperm motility in the reproductive tract. Biology of reproduction 84(5): 10051015.

Zeh, J.A., Bonilla, M.M., Adrian, A.J., Mesfin, S., Zeh, D.W. 2012. From father to son: transgenerational effect of tetracycline on sperm viability. Scientific Reports 2: 375 .

Recibido: 02.01.2018

Aceptado: 13.09.2018 